\title{
Ueber Immunisirung und Heilung von Versuchsthieren bei der Diphtherie.
}

\author{
Von \\ Stabsarzt Dr. Behring, \\ Assistenten am Institut fär Infectionskrankheiten, \\ und \\ Stabsarzt Dr. Wernicke, \\ Assistenten am hygienischen Institut der Uuiversităt Berlin.
}

Bei unseren gemeinschaftlichen experimentellen Diphtheriestudien an Thieren sind wir in Bezug auf die Fragen der Immunisirungs- und Heilungsmöglichkeit gegenüber der Diphtherie zu einem gewissen Abschluss gekommen, und es scheinen uns die Ergebnisse unserer Studien von solcher Art zu sein, dass man nunmehr auch an ihre Verwerthung für den durch die Diphtherie bedrohten und für den diphtheriekranken Menschen denken kann.

Obwohl, wie wir gestehen, dies das Ziel gewesen ist, welches uns von Anfang an bei unseren Arbeiten geleitet hat, und welches wir von da $a b$, wo wir es für erreichbar halten durften, keinen Moment mehr aus dem Auge verloren haben, so sind doch bis jetzt von uns keinerlei Versuche gemacht worden, um unsere Methoden bei der Diphtheriebehandlung auf den Menschen anzuwenden.

Die Möglichkeit dazu ist jetzt zwar thatsächlich vorhanden.

Nachdem wir zuerst an kleineren Thieren, nämlich an Meerschweinchen und Kaninchen, Methoden gefunden haben, mit Hülfe deren es gelingt, einen sehr hohen Grad von Diphtherieimmunität zu erzeugen, und nachdem wir im Blut der immun gewordenen Thiere ein so sicher und schnell wirkendes Immunisirungs- und Heilmittel für die Diphtherie von Versuchsthieren nachgewiesen haben, wie bis dahin kaum ein solches für möglich gehalten worden ist, machten wir uns an die Aufgabe, zum Zweck 
Behring U. Werniche: IMMUUNisirdng v. Versuchsthieren U. S. W. 11

der Gewinnung grösserer Mengen dieses Mittels, grosse von Natur für die Diphtherieinfection sehr empfängliche Thiere zu immunisiren.

Es ist uns das an Schafen gelungen. Dẹr Immunisirungsprocess ist bei zwei von diesen Thieren soweit vorgeschritten, dass wir unter Voraussetzung ähnlicher Verhältnisse beim Menschen mie beim Versuchsthier genügende Mengen von Blut zur Verfügung haben, um einige diphtheriekranke Kinder damit zu behandeln.

Wir sind jedoch zu der Ueberzeugung gekommen, dass es die Kräfte und Mittel unserer privaten Thätigkeit übersteigt, den Versuchen eine solche Ausdehnung zu geben, um mit praktischem Erfolge unsere Diphtheriebehandlungsmethode auf den Menschen zu übertragen, da mit der Behandlung einiger weniger Fälle kaum über die zweckmässigste Art der Dosirung und Applicationsweise ein abschliessendes Crtheil zu gewinnen sein wird. Schon jetzt aber haben unsere Arbeiten einen für unsere Leistungsfähigkeit übergrossen Umfang angenommen; und so haben wir uns entschlossen, eine gewisse Entsagung zu üben und weitere Kreise für die Angriffnahme von Versuchen im grossen Massstabe zu interessiren, durch welche unser Diphtherieimmunisirungs- und Heilmittel auch für den Menschen nutzbar gemacht werden kaun.

$\mathrm{Zu}$ diesem Zweck theilen wir im Folgenden die bisher erreichten Resultate und ihre wissenschaftliche Grundlage mit.

Die mühevollen Untersuchungen Boer's hatten uns ron der Aussichtslosigkeit überzeugt, unter den Präparaten der Pharmakopoe und überhaupt unter fertigen chemischen Präparaten eines zu finden, welches eine derartige Heilwirkung gegenüber der Diphtherie ausübte, dass man es als ein Specificum gegen dieselbe gebrauchen könnte.

Keines war im Stande, eine Allgemeinwirkung auf diphtherieinficirte Thiere auszuüben.

Nach einem solchen Mittel aber, das vom Blut aus überall im Organismus die kranken Stellen trifft, musste gesucht werden, nachdem festgestellt war, dass bei diphtherieinficirten Individuen das todbringende Gift im Blute kreist und nachweisbare Veränderungen im ganzen Organismus hervorruft.

Dass auch der diphtheriekranke Mensch nicht etwa - wenigstens nicht immer - bloss an einer Localerkrankung leidet, dafür wurde uns noch neuerdings im Institut für Infectionskrankheiten der Beweis geliefert. Es liessen sich aus allen Organen eines an Rachen- und Kehlkopfdiphtherie verstorbenen Kindes Diphtheriebacillen herauszüchten. 
Nag man sich nun den Diphtherietod, insofern er nicht durch ein reines Athmungshinderniss erfolgt, als einen Herztod vorstellen, oder mag man die Wirkung sich in der Weise denken, dass das in den Blutkreislauf gelangte Diphtheriegift das Blut so verändert, dass es zur Ernährung aller lebenswichtigen Organe untauglich wird - immer müssen wir die Diphtherie als eine. Allgemeinerkrankung ansehen, bei welcher wir mit ausschliesslich local wirkenden Mitteln therapeutisch nicht weit kommen. Wie gross auch die Zahl derselben inzwischen geworden ist, das Endresultat ist bis jetzt noch bei allen Behandlungsmethoden das gleiche geblieben: „Die leichten Fälle kommen durch, die schweren Fälle sterben."

Ob auch die schweren Fälle der Therapie zugänglich werden? Wir wissen es noch nicht; wenn das aber jemals der Fall sein soll, so wird es sicherlich nur durch ein solches Mittel ermöglicht werden, welches die Fähigkeit besitzt, die Krankheitsursache im Innern des Organismus unschädlich zu machen, mit anderen Worten: „den lebenden kranken Menschen im Innern zu desinficiren."

Die Wahrscheinlichkeit, ein solches Mittel zu finden, war von vormherein keine sehr grosse; galt es doch bis in die jüngste Zeit als ein überall acceptirtes klinisches Dogma, dass eine ,allgemeine innere Desinfection" für immer unmöglich bleiben werde.

Die Jröglichkeit hierfür wurde aber doch etwas näher gerückt durch den bei einigen Infectionskrankheiten erbrachten Nachweis, dass die Immunität in einem innigen Zusammenhange steht mit gewissen Eigenschaften des zellfreien Blutes, dass nämlich das ron lebenden Elementen befreite Blut mancher immuner Thiere vermöge seiner chemischen Beschaffenheit die Fähigkeit besitzt, sei es die lebenden Krankheitserreger, sei es das specifische Gift, kurz die Úrsache der Krankheit, gegen welche sie immun sind, unschädlich zu machen.

Von dieser Thatsache ausgehend, versuchten wir Heilwirkungen mit dem Blute solcher Thiere zu erzielen, die von Natur gegen Diphtherie immun sind. Wir haben das Blut von Mäusen, Ratten, Hunden, später das Blut von allen Thieren, die uns im Laboratorium oder im Schlachthause zugänglich waren, untersucht; mit keiner einzigen Blutart aber bekamen wir ein positives Resultat.

Dagegen zeigten sich andeutungsweise therapeutische Resultate, als wir das Blut solcher Thiere zur Behandlung von diphtherieinficirten Meèschweinchen nahmen, die wir durch sehr frühzeitige Localbehandlung mit Jodtrichlorid und mit Goldnatriumchlorid geheilt und dadurch bis $\mathrm{zu}$ einem "freilich nur geringen Grade immunisirt hatten. 
Es war nur ein Fingerzeig uns zunächst damit gegeben; denn über eine mässige lebensverlängernde Wirkung kamen wir lange Zeit nicht hinaus.

Aber wir sahen bald, wie die Resultate besser wurden, je höher der Grad der Diphtherieimmunität unserer Meerschweinchen wurde; und so war uns, um zum Ziele zu gelangen, die nächste Aufgabe bestimmt vorgezeichnet:

Es galt zuerst, eine zweckmässigere Immunisirungsmethode zu finden, als die vorher angedeutete, welche in der Heilung diphtherieinficirter Thiere besteht.

Wir haben nun im Laufe der Zeit eine grosse Zahl wissenschaftlich zum Theil sehr interessanter Methoden keunen gelernt, mit Hülfe deren man die Widerstandsfähigkeit von diphtherieempfänglichen Thieren erhöhen kann.

Diejenige Methode jedoch, welche wir jetzt ausschliesslich anwenden, und die uns zwar sehr langsam aber sicher unseren Zweck erreichen lässt, schliesst sich eng an die Jodtrichloridbehandlung diphtherieinficirter Thiere an.

Fragt man sich, wie die Immunisirung hierbei zu Stande kommt, so ist eine andere Deutung kaum möglich, als dass die durch das Jodtrichlorid - wie wir des öfteren feststellen konnten - im Thierkörper nicht abgetödteten Diphtheriebacillen weiter fortfahren ihre Stoffwechselproducte zu produciren, dass dieselben jedoch eine Veränderung durch das Jodtrichlorid erfahren. Das Diphtheriegift wird, wie wir sagen, abgeschwächt.

Es lag nun der Versuch nahe, ob man nicht diese Einwirkung des Jodtrichlorids auf das Diphtheriegift ausserhalb des Organismus verlegen und den Vorgang der Immunisirung für das Thier ungefährlicher machen kann, indem man ihm jodtrichloridbehandelte Diphtherieculturen applicirt, statt es zuerst mit Diphtherie zu inficiren und hinterher mit Jodtrichlorid zu behandeln.

Gleich die ersten Versuche waren sehr ermuthigend, und es galt nun bloss noch das Verfahren weiter auszubilden. Indem wir bezüglich der Einzelheiten desselben auf die Geschichte eines Theiles der immun gewordenen Thiere, welche im Folgenden aufgeführt sind, verweisen, möchten wir nur hervorheben, dass es ziemlich gleichgültig für das Gelingen der Versuche ist, ob man bacillenhaltige oder ganz keimfreie Culturen zum Zwecke der Immunisirung wählt. Das Wesentliche bei unseren Resultaten ist nur der Grad der Giftigkeit derselben. Wir arbeiten seit einem Jahre mit Culturen, die mindestens 4 Monate im Brutschrank gestanden haben und sehr starke Giftigkeit besitzen. 
Durch Zusammengiessen der Culturen aus einer grossen Zahl von Einzelkolben und Filtriren derselben durch Filtrirpapier, haben wir uns keimfreie bez. keimarme Stammflüssigkeit hergestellt, die`wir durch Zusatz von Carbolsäure (bis zu einem Gehalt von 0.5 Procent) conserviren und in grosser Menge vorräthig halten.

Von derjenigen diphtheriegifthaltigen Flüssigkeit, welche wir gegenwärtig benutzen und die weiter nichts ist, als das Filtrat alter Diphtherie-Bouillon-Culturen, hatten wir vor 9 Monaten festgestellt, dass $0.15^{\mathrm{ccm}}$ derselben genügen, um ein ausgewachsenes Meerschweinchen nach circa 4 Tagen zu tödten; aber noch 0.01 war so giftig, dass auch ganz grosse Meerschweinchen nach Ablauf von mehreren Wochen unter wenig charakteristischen Krankheitserscheinungen starben. Regelmässig fand sich dann Leberrerfettung hohen Grades bei den an diesen kleinen Dosen verendeten Thieren.

Dieser Grad der Giftigkeit hat sich gegenwärtig, also nach 9 Monaten, noch nicht wesentlich geändert, so dass wir während dieser ganzen Zeit mit einer Flüssigkeit von genügend constantem Wirkungswerth arbeiten konnten. Das hat selbstrerständlich sehr grosse Vortheile; wir konnten beispielsweise unsere ganzen Versuche aus früheren Zeiten jetzt noch immer verwerthen, was gar nicht möglich wäre, wenn wir mit einem Diphtheriegift von inconstantem Werth in den verschiedenen Phasen unserer Untersuchungen zu thun gehabt hätten.

Wir sind auch der Meinung, dass nur diesem Umstande es zu verdauken ist, wenn wir schliesslich $\mathbf{z u}$ befriedigenden Resultaten gekommen sind; in der langen Immunisirungsperiode, welche dem Eintritt desjenigen immunen Zustandes voraufgeht, den wir für unsere Zwecke fordern müssen, haben wir es für nöthig gefunden, die Dosis des jodtrichloridbehandelten Diphtheriegiftes jedes Mal so gross zu nehmen, dass sie eine deutliche locale und allgemeine Reaction auslöst, und wir machten dabei die Erfahrung, dass man mit der Stärke der Dosis nach Ablauf der jedesmaligen Reaction stetig steigen muss, um den gleichen Effect zu erreichen. Bei mangelnder Reaction ist der immunisirende Effect sehr gering oder gar nicht vorhanden; bei zu starker Reaction, die sich namentlich in fortschreitender Abmagerung der Versuchsthiere aussert, wird in der Regel die Immunisirung gänzlich vereitelt; auch wenn das Thier nicht direct zu Grunde geht, findet man bei der nächstmaligen Prüfung noch nach Monaten die Empfindlichkeit gegen das Immunisirungsmittel nicht vermindert, sondern erhöht, und wenn man solche Thiere tōdtet, so lassen sich regelmässig parenchymatôse Veränderungen der Bauchorgane, namentlich der Leber constatiren. 
Hier nun die richtige Mitte in der Dosirung zu beobachten, ist nur dann möglich, wenn man von Anfang bis zu Ende mit einem Mittel arbeitet, welches einen genau bekannten Wirkungswerth besitzt.

Was die in den Einzelversuchen angegebenen Zahlenwerthe für den Jodtrichloridzusatz betrifft, so ist dazu noch zu sagen, dass die Dauer der Einwirkung des jedes $\mathrm{Nal}$ in Frage kommenden Jodtrichloridzusatzes bei unserem jetzt geübten Immunisirungsverfahren mindestens zwei Tage beträgt, höchstens vier Wochen. Es hat sich uns im Laufe der Zeit gezeigt, dass zur Erlangung eines einigermassen constant bleibenden Grades der. Abschwächung des Diphtheriegiftes 36 bis 48 Stunden vergehen. Innerhalb dieser Zeitdauer nimmt die Giftabschwächung gradatim zu; darüber hinaus kann man für die hier in Frage kommenden Zwecke annehmen, dass eine wesentliche Veränderung der toxischen Wirkung nicht mehr zu beobachten ist, zumal wenn man die Mischungen im Eisschrank stehen lässt.

Unter Berücksichtigung aller dieser Einzelheiten haben wir im Laufe der letzten Monate Verluste dureh den Act der Immunisirung nicht mehr zu beklagen gehabt; namentlich ist bei neun Hammeln, welche wir bis jetzt immunisirt haben, zu keiner Zeit eine Gefährdung ihres Gesundheitszustandes eingetreten.

Bei Kaninchen aber sind wir bis jetzt selbst bei strengster Beobach. tung aller vorher erwähnter Cautelen nur in wenigen Fällen zum Ziele gekommen, und wir sahen uns schliesslich genöthigt, bei diesen Thieren für die Immunisirung andere Verfahren zu wählen - nicht mit absolut sicherem, aber doch für die meisten Fälle mit gutem, z. Th. mit hervorragend gutem Erfolg.

Das eine Verfahren besteht darin, dass man längere Zeit hindurch täglich einmal unverändertes Diphtheriegift in den Magen der Thiere hineinbringt. Die Dosirung ist am zweckmässigsten eine solche, dass die Einzelgabe gleich zu Anfang um ein Mehrfaches diejenige Dosis übersteigt, welche für dasselbe Thier bei subeutaner Injection tödtlich sein würde, dass man sehr langsam ansteigt und sofort die Behandlung aussetzt, wenn Abnahme des Körpergewichts eintritt. Nach Rückkehr des Gewichts zur Norm wird dann mit der stomachalen Darreichung wieder fortgefahren.

Eine andere Art der Immunisirung von Kaninchen werden wir wegen der ausgezeichneten Resultate, welche sie in einigen Fällen ergeben hat, von Neuem aufnehmen, nachdem sie in Folge anderer aussichtrersprechender Methoden zeitweilig in den Hintergrund getreten war.

Dieselbe besteht darin, dass die Thiere mit dem getrockneten, dann gepulverten and eine Stunde auf $77^{\circ}$ erhitzten Kalkniederschlag geimpft 
werden, den wir aus sehr giftigen, keimfreien Culturen gewonnen haben, nachdem die letzteren in der von Roux und Yersin angegebenen Weise mit Calciumchloridlösung versetzt waren.

Eine ganz kleine Menge, $0.005 \mathrm{grm}$, dieses Diphtheriegift-Kalkpulvers in eine Hauttasche am Bauch verimpft, genügt, um eine über die ganze Bauchhaut ausgebreitete ausserordentlich starke phlegmonöse Entzündung herrorzurufen.

Nach Art des in Heilung übergehenden Erysipels beim Menschen verschwindet im Laufe von 8 Tagen diese Entzündung, und wenn man nun weitere 8 Tage abwartet und dann von neuem impft, dann tritt keine Entzündung, oder nur eine ganz geringe flache und local begrenzte, auf. Später kann man dann grössere Mengen des erhitzten Kalkpulvers in eine Hauttasche einbringen, welche für Controlthiere unfehlbar tödtlich sind und bei denselben zu multiplen eitrigen Herderkrankungen in den Lungen und namentlich auch in der Leber führen, ohne dass die vorbehandelten Kaninchen Schaden erlejden, und wenn man nun die Thiere mit lebender Cultur in einer für frische Kaninchen innerhalb ron 3 bis 4 Tagen tödtlich wirkenden Menge impft, so bleiben sie gesund.

Das Blut eines so immunisirten Kaninchens ist es gewesen, mit welchem wir die ausserordentlich gủnstige Heilwirkung und Immunisirung bei den Meerschweinchen Nr. 17 und 18 erzielt haben.

Wie aber auch die Immunisirung erreicht sein mag und gleichgültig, ob bei Meerschweinchen, Kaninchen oder Hammeln, das Endresultat bezüglich der schützenden und heilenden Wirkung des Blutes der immun gemachten Thiere war qualitativ stets das nämliche; und nur quantitativ war es verschieden: Genau entsprechend dem Immunitätsgrade. der blutliefernden Thiere gestalteten sich die therapeutischen Erfolge.

Wir haben uns in letzter Zeit gewöhnt, die so nothwendige zahlenmässige Bestimmung des. Immunitätsgrades etwas anders zu treffen als früher.

Ursprünglich bezeichneten wir die Immunität mit der Zahl 1, 2 u. s. w. nach Ehrlich's Vorgang, je nachdem die immunisirten Thiere nur die einfache Menge oder ein Multiplum der tödtlichen Minimaldosis an lebender Diphtheriecultur oder an Diphtheriegift vertirugen.

Gegenwärtig machen wir das anders.

Wir entnehmen den immunisirten Thieren Blutproben und injiciren. das daraus gewonnene Serum in steigender Menge einer Reihe von Meerschweinchen in die Bauchhöhle oder unter die Haut unter Berūeksich- 
tigung des Körpergewichts derselben, so dass z. B. ein Meerschweinchen Serum im Verhältniss von 0.5:100 Körpergewicht, ein zweites $1: 100$, ein drittes 2:100 u. s. w. bekommt. Einen Tag später werden dann diese Serum-Meerschweinchen mit der gleichen Menge einer zwei Tage lang im Brütschrank gewachsenen Diphtheriebouilloncultur inficirt, und zwar mit solcher Menge, von der wir vorher festgestellt haben, dass sie ausgewachsene Meerschweinchen mit Sicherheit in 3 bis 4 Tagen unter den Erscheinungen der Diphtherie tödtet.

Von der Cultur, mit welcher wir in letzter Zeit arbeiten, ist diese Dosis $0.0125^{\mathrm{ccm}}$.

Um diese Dosis recht genau abmessen zu können, verfahren wir in der Weise, dass wir zunächst einen Theil der Diphtheriebouilloncultur mit 19 Theilen Wasser verdünnen und dann von dieser Verdünnung $0 \cdot 25^{\mathrm{cm}}$ subcutan mit einer Koch'schen Spritze den Meerschweinchen injiciren. Dieselben zeigen dann, wenn sie nicht mit Serum rorbehandelt sind, nach 24 Stunden ein leichtes, ganz weiches Oedem an der Stelle der Infection, welches an den folgenden Tagen immer mehr zunimmt, auch sich in eine härter werdende Infiltration umwandelt und zur Schwartenbildung führt. Im Laufe des dritten spätestens des vierten Tages sterben dann mittelgrosse Meerschweinchen unter den Erscheinungen der Dyspnoe. Schon längere Zeit vor Eintritt des Todes sitzen sie zusammengekauert, mit struppigem Haar, und wenn sie in die Hand genommen werden, so fühlen sie sich kalt und schlaff an. Temperaturmessungen ergeben in diesem Stadium regelmässig subnormale Temperaturen.

Bei der Section ist ein sehr regelmässiger Befund Schwartenbildung an der Infectionsstelle; statt der Schwartenbildung wird nur bei sehr schnell verlaufender Krankheit Oedemflüssigkeit gefunden; ferner fehlt fast nie ein beträchtlicher dünnflüssiger oder auch fadenziehender Erguss in die Pleurasäcke, zuweilen auch in den Pericardialsack. Die Lungen sind meist marmorirt und stellenweise atelektatisch; alle Bauchorgane sind stark mit Blut überfüllt und sehr regelmässig findet man an Stelle der bei gesunden und an anderen Krankheiten verendeten Thieren weiss aussehenden Nebennieren dieselben fleckig geröthet, oder auch ganz dunkelroth; dabei sind dieselben vergrössert.

Bleiben nun die mit Serum vorbehandelten Thiere am Leben und und zeigen sie local keine Infiltration, auch keine der oben geschilderten allgemeinen Krankheitssymptome, so betrachten wir die angewendete Serummenge als zur Immunisirung genügend.

Um aber auszudrücken, welchen Grad der immunitätverleihenden Wirkung das Serum besitzt, wählen wir die kleinste Menge, mit welcher dieser Effect noch erreicht wird. Zeitschr. f. Hygiene. XII. 
Falls also bei $0.5: 100 \cdot(1: 200)$ die Thiere zwar am Leben bleiben, jedoch locale und allgemeine Krankheitserscheinungen erkennen lassen, während dieselben bei der Dosis ron 1:100 und 1:50 fehlen, so sagen wir, dass die immunitätverleihende Wirkung des Serums 1:100 ist.

Fin solches Verhältniss hatten wir beispielsweise für das Serum des Hammels II vom 12./XII. 1891 durch Vorversuche festgestellt. Es ist das dasselbe Serum, welches bei den Meerschweinchen Nr. 35 bis 38 und bei Nr. 39 u. s. w. zur Anwendung kam.

Aus mehrfachen Gründen erscheint es uns zweckmässig, das Serum mit einem Zusatz von solchen conservirenden Mitteln zu versehen, die das Verderben desselben durch Bacterienvegetation verhindern. Für diesen Zweck hat sich uns der Zusatz von Carbolsäure bis zu einem Gehalt von 0.5 Procent vortrefflich bewährt. Ebenso wenig wie bei der. Aufbewahrung des Diphtheriegifts hat sich beim Diphtherieheilserum bis jetzt eine. deutlich in Erscheinung tretende Abnahme der Wirkung ergeben. . Freilich erstrecken sich unsere Erfahrungen für das letztere bis jetzt erst auf eine Zeitdauer von nicht länger als sechs Wochen.

Mit solchem Carbol-Heilserum, das aus dem Blut von immunisirten Meerschweinchen, Kaninchen, Hammeln stammte, haben wir zur Entscheidung einer Reihe principiell wichtiger Fragen weit über 100 Einzelversuche angestellt.

Wir zählen einige dieser Fragen, deren Beantwortung wir als schon jetzt erledigt ansehen können, hier auf.

Die allerersten Versuche nach Feststellung der Thatsache, dass wir überhaupt ein immunitätrerleihendes Blut in Händen hatten, bezogen sich auf die Orientirung darüber, ob etwa die heilbringende Substanz fermentähnliche Wirkung besitzt, der Art, dass sie nur den Anstoss zu gewissen Veränderungen im behandelten Organismus liefert, die dann ihrerseits erst die Immunität bedingen. Etwas derartiges glauben wir für diejenige Immunität annehmen zu dürfen, welche wir mit dem Diphtheriegift zu Wege bringen.

Das ist nun für das Heilserum ganz sicher nicht der Fall. Vielmehr haben immer erneute Experimente ergeben, dass es direct das Serum ist, welches Immunität und Heilung gewährt.

Durch die Serumzufuhr geben wir einem Thiere ein anderes Blut und damit gewisse Eigenschaften und Fähigkeiten-desjenigen Individuums, von welchem das Serum gewonnen ist.

Dementsprechend kommen wir nicht mit einfachen Blutimpfungen aus, sondern wir müssen ausgerechnete Serummengen transfundiren; die Berechnung aber geschieht in der Weise, dass man zunāchst feststellt, welchen Grad der Immunität das blutgebende Thier besitzt. Hat beispiels- 
weise ein Meerschweinchen eine Immunität $=10$ (nach Ehrlich's Berechnung), so müssen wir mindestens den zehnten Theil der gesammten Blutmenge dieses Thieres einem gleich grossen anderen Meerschweinchen injiciren, wenn dasselbe eine Immunität $=1$ erhalten soll.

Fernerhin kam es uns darauf an, festzustellen, welcher Antheil an immunitätverleihender Substanz im Serum und welcher im Blutkuchen enthalten ist. Da hat sich ergeben, dass die Hauptmenge derselben im ausgeschiedenen Serum wieder gewonnen wird; denn das volle Blut zeigte geringere Wirkung als gleiche Mengen des daraus gewonnenen Serums, und der getrocknete und hinterher mit kochsalzhaltigem Wasser verriebene Blutkuchen hat uns nur geringe immunisirende Leistungsfähigkeit erkennen lassen.

Von besonderer Wichtigkeit war dann das Verhältniss, welches bei gleichen Serumquantitäten zwischen ihrer immunitätverleihenden und heilbringenden Kraft besteht. Auch in Bezug auf diese Frage bekamen wir ganz unzweideutige Antwort. Man braucht zur Erreichung. von Heileffecten grössere Mengen Serum, als fūr die Immunisirung; und zwar sind die zur erfolgreichen Behandlung von vorher diphtherieinficirten Meerschweinchen erforderlichen Serummengen um so grösser, je später nach der Infection die Behandlung eingeleitet wird.

Bei solchen Infectionen, an welchen Meerschweinchen nach 3 bis 4 Tagen zu Grunde gehen, wurde sofort nach der Infection das $1 \frac{1}{2}$ bis 2 fache derjenigen Dosis zur glatten Heilung gebraucht, die zur einfachen Immunisirung ausgereicht hatte; acht Stunden nach der Infection mussten wir das 3 fache nehmen; und wenn wir erst nach 24 bis 36 Stunden die Behandlung begonnen haben, so mussten wir - refracta dosi - bis zum 8 fachen steigen.

Was die Dauer der Immunität betrifft, wenn Meerschweinchen bloss Serum bekommen und keine nachfolgenden Diphtherieinfectionen erlitten hatten, so können wir hierüber noch nichts Endgültiges aussagen. Mindestens einige Wochen dauert in diesem Falle die Immunität an.

Sind serumbehandelte Thiere hinterher mit Cultur geimpft, oder haben sie Diphtheriegift bekommen, so muss man diesem Umstande hei der Constatirung der Dauer der Immunität Rechnung tragen. Es hat sieh da die wichtige Thatsache ergeben, dass durch die Behandlung mit Cultur oder Gift, wenn dieselbe gut überstanden wird, die Immunität zunimmt.

Auf diese Weise sind wir zu einer neuen sehr viel versprechenden Immunisirungsmethode gekommen, welche darin besteht, dass man zuerst diphtherieempfänglichen Thiere durch Heilserum einen gewissen geringeren 
Grad ron Immunität verschafft, und dass man dieselben dann in entsprechenden Zeitintervallen mit immer grösseren Culturmengen inficirt.

Andere Versuchsreihen wurden zu dem Zweck angestellt, um das Verhältniss der immunisirenden und heilenden Leistungsfähigkeit des Serums bei subcutaner und bei intraperitonealer Injection zu bestimmen. Wir fanden, dass bei noch nicht inficirten und bei sofort nach der Infection in Behandlung genommenen Thieren beide Applicationsarten ziemlich gleich wirksam sind, dass jedoch bei solchen Thieren, die, wenn sie schon krank sind, behandelt werden, die intraperitoneale Injection unvergleichlich mehr leistet, als die subcutane. Wahrscheinlich hat diese Thatsache darin ihre Ursache, dass bei den kranken Thieren, namentlich solchen mit ausgebreitetem Oedem, die Resorption vom subcutanen Hautgewebe aus viel zu langsam erfolgt.

Wir wollen nur noch das Ergebniss einiger Versuchsreihen anführen, die bei gleichbleibenden Serummengen uns zeigen sollten, wie sich das Verhältniss der immunisirenden und heilenden Wirkung gestaltet, wenn die Infection mit lebender Cultur geringer oder stärker war. Soviel wir bis jetzt erkennen können, wird der Heileffect fast in arithmetischer Progression geringer mit der Steigerung der inficirenden Culturmenge; etwas weniger dagegen macht sich die letztere in ihrem Einfluss auf die zur Immunisirung anzuwendende Serummenge geltend.

Wir versuchen noch, auf eine grosse Zahl anderer und zum Theil sehr wichtiger Fragen durch Thierversuche Auskunft $\mathrm{zu}$ erlangen. Besonders dringlich ist die Feststellung des Einflusses von physikalischen und chemischen Agentien auf die Wirkung des Heilserums. Wir haben gefunden, dass eine solche Vorprüfung denjenigen Untersuchungen voraufgehen muss, die sich mit der Isolirung der wirksamen Körper im Serum befassen. Nach dieser Richtung sind wir zu einem abschliessenden Ergebniss noch nicht gekommen.

Wie man uns wohl zugeben wird, sind inzwischen schon die Arbeiten $\mathrm{zu}$ einem sulchen Umfang gediehen, dass uns die Theilnahme an denselben von anderer Seite erwünscht sein muss.

Da wir aber annehmen dürfen, dass anderwärts die Vorbedingung für die Möglichkeit der Mitarbeit noch nicht existirt, wegen des Mangels an hoch immun gewordenen, ursprünglich diphtherieempfänglichen Thieren, so haben wir uns entschlossen, diejenigen Methoden, welche uns zum Ziele geführt haben, hier mitzutheilen.

Zur Mllustration dieser Methoden führen wir nun im Folgenden eine grössere Versuchsreihe auf, welche von Anfang bis zum Ende Herr 
Geheimrath Koch auf unsere Bitte mitbeobachtet hat, und die zum Theil wenigstens, auch mehrere andere Herren mit angesehen haben.

Die Heilresultate, soweit sie aus der Zahl der am Leben gebliebenen Thiere beurtheilt werden kōnnen, sind nicht so gut geworden, wie wir sie haben wollten; nicht etwa deswegen, weil wir uns in dem Immunitätsgrade unserer blutliefernden Thiere oder in der Heilwirkung unseres Serums getäuscht hätten, sondern deswegen, weil wider unsere Absicht die Infection - der übrigens in genau gleicher Weise inficirten 50 Thiere zu stark gewesen ${ }^{-}$ist, wie daraus zu ersehen ist, dass die Controlthiere, auch die grössten, schon in Zeit von 19-30 Stunden sämmtlich starben; die vor uns zu Heilzwecken angewendeten Serummengen waren aber auf eine solche Infection berechnet, die mittelgrosse Meerschweinchen erst nach 3-4 Tagen tödten.

In anderer Beziehung aber ist diese etwa um's dreifache zu starke Infection auch wieder für die hier ausgeführten Versuche sehr lehrreich. Sie zeigt, dass diejenigen Thiere, welche wir wegen der bei ihnen supponirten hohen Immunität vorangestellt haben $(1-7)$, lückenlos die Infection ohne jede Reaction überstanden. Sie zeigt ferner die uns selbst in angenehmer Weise überraschende Thatsache, dass die mit Kaninchenserum vor vier Monaten vorbehandelten Thiere, die freilich ausserdem Diphtherieinfectionen überstanden haben, gleichfalls sehr hohe Immunität besitzen, sowie weiter, dass wir durch unser Hammelserum schon recht beträchtliche Immunisirungseffecte (Nr. 35 u. 37) und Heilerfolge erzielen können.

Nach den vorangehenden Bemerkungen brauchen wir bloss anzudeuten, dass wir es vollkommen in der Hand haben, die Versuchsanordnung so zu gestalten, dass Fehlerfolge ganz ausbleiben, sei es dadurch, dass wir wirksameres Serum nehmen, oder die Dosis eines weniger wirksamen steigern, oder indem wir die Infection weniger stark machen. Zum Beweise dessen dienen die Versuche Nr. 17, 18, 23 und 31 unter den lebend gebliebenen Thieren der ersten Versuchsreihe.

Ausserdem fügen wir auch noch eine zweite Versuchsreihe an, für welche z. Th. das gleiche Hammelserum (II, 12./XII.) verwendet wurde, z. Th. aher auch sehr wirksames Meerschweinchenserum.

Ebenso versteht es sich ganz von selbst, dass wir zur Gewinnung immer wirksameren Serums, so dass schliesslich auch für grössere Individuen innerhalb des praktisch Anwendbaren liegende Dosen zur Heilung genügen, nur Geduld nöthig haben; es ist vorläufig noch gar nicht abzusehen, wie weit beispielsweise bei Hammeln die Immunität getrieben werden kann; vorläufig sind wir noch sehr weit entfernt von der Grenze, bei welcher dieselben aufhören, auf unsere Culturen zu reagiren; so lange wir aber noch Reactionen, sei es auf das Diphtheriegift, sei es auf 
lebende Culturen eintreten lassen können, so lange wimmt auch die Immunität und damit die Wirksamkeit des Blutes noch immer zu.

Wir sind nicht wenig zufrieden, dass es uns innerhalb der wenigen Monate, während welcher wir überhaupt an Hammeln arbeiten, gelungen ist, auch nur zu den aus den nachfolgenden Tabellen erkennbaren Resultaten zu kommen.

Bevor wir nun zum Bericht über die hier im Folgenden mitgetheilten Einzelversuche übergehen, wollen wir einige Dinge, welche sich immer wiederholen, vorweg erörtern.

Da haben wir zunächst genauere Angaben darüber zu machen, wie wir unsere Thiere mit Diphtherie inficiren.

Wir verwenden, wenn es uns auf präcise, zahlenmässig zu berechnende Ergebnisse ankommt, principiell nur Bouillonculturen und zwar zweitāgige. Unsere Bouillon ist die in der gewöhnlichen Weise aus Fleischinfus mit 1 Procent Pepton hergestellte. Zar Impfung derselben rerwenden wir Agarculturen.

Es empfiehlt sich zur Abimpfung immer die nämliche Agarcultur wieder zu verwenden. Eine Abnahme der Virulenz haben wir im Laufe ron 3 Monaten auf Nähragar, der mit 1 Procent Pepton - ohne Glycerinzusatz hergestellt ist - nicht beobachtet; andererseits ist auch eine Zunahme der Virulenz in unseren Versuchen nicht in unzweideutiger Weise in Erscheinung getreten.

Dieses Constantbleiben der Virulenz kann nicht in gleicher Weise ron den Bouillonculturen behauptet werden. Zwar eine Abnahme haben wir auch hier nicht gesehen. Dagegen ist es gegenwärtig für uns eine ganz feststehende Thatsache, dass die von alten Bouillonculturen abgeimpften frischen Culturen stärkere inficirende Kraft bekommen.

Wir arbeiten seit $1 \frac{1}{2} \mathrm{Jahr}$ jetzt mit einer Diphtheriecultur, die ron einem sehr schnell an Diphtherie verstorbenen Kinde stammt, und die wir aus einer Trachealmembran herausgezüchtet haben, welche ausser Diphtheriebacillen keine anderen Bacterien enthielt.

Im Juni 1890 nun mussten wir mindestens $0.1 \mathrm{~cm}$ einer 2 Tage im Brütschrank gewachsenen Bouilloncultur subcutan injiciren, um damit Meerschweinchen innerhalb ron 3-4 Tagen zu tōdten; im Mai 1891 genügten aber schon $0.025^{\mathrm{ccm}}$, um denselben Effect zu erreichen. Die Virulenz hatte sich demnach in der Zeit ron 11 Monaten vervierfacht.

Wir schreiben diese Steigerung der Infectionskraft dem Umstande zu, dass wir von Zeit zu Zeit Abimpfungen von sehr alten im Brütschrank gewachsenen Culturen rorgenommen haben - ron 5 Monate bis zu 7, ja bis 11 Monate alten - und dass wir die so gewonnenen Culturen 
weiter züchteten; und wir erklären uns die Virulenzzunahme der letzteren in folgender Weise.

Man macht bei der Abimpfung ron sehr alten Diphtheriebouillonculturen die Erfahrung, dass einfache Uebertragung der sehr bacillenreichen Flüssigkeit mittels einer Platinnadel oder auch mittels einer Platinöse auf Agar sehr häufig resultatlos bleibt; es wächst nichts darauf. Auch die Uebertragung so kleiner Mengen in Bouillon ergiebt in vielen Fällen ein negatives Resultat; in allen Fällen aber wird man während des ersten und zweiten Tages nach der Ueberimpfung makroskopisch ein deutliches Wachsthum vermissen. Erst am 3. bis 5. Tage zeigt sich deutlich Schüppchenbildung an der Oberfläche der Bouillon oder auch eine reichlichere Trübung der ganzen Bouillon in einer gewissen Zahl von Reagensröhren, die man geimpft hat.

Verwendet man zur Impfung $0.5^{\mathrm{ccm}}$ der alten Cultur, so wird man nie das Wachsthum in einer sonst geeigneten Bouillon ansbleiben sehen.

Aus alledem schliessen wir, dass eine grosse Zahl von Bacillen in den alten Diphtheriebouillonculturen abstirbt und der noch lebend bleibende Rest eine Beeinträchtigung seiner regetativen Eigenschaften erfahren hat. Dieselben werden aber sehr bald bei den noch lebenden Bacillen restituirt, und schon die 2. Generation wächst überaus schnell und üppig.

Im Gegensatz zu den bisher geltenden Anschauungen steht durchaus nicht die Ueppigkeit des Wachsthums auf künstlichen Nährböden in umgekehrten Verhältniss zur Virnlenz; eher könnte man aus unseren Beobachtungen das Gegentheil schliessen.

Aber nicht in dieser Zunahme der vegetativèn Energie erblicken wir die wesentliche Ursache dafür, dass wir jetzt mit sehr viel kleineren Culturmengen gleich starke Infectionen hervorrufen können als früher; vielmehr nehmen wir an, dass in den alten sehr giftreichen Bouillonculturen functionelle Aenderangen in den Eigenschaften der Diphtheriebacillen eintreten, und wir greifen somit auf die Anpassungstheorie als Erklärungsprincip für die Virulenzzunahme zurück; daneben mag vielleicht auch als secundäre Erklärung dieser Erscheinung die Selectionstheorie zu Hülfe genommen werden können in dem Sinne, dass nämlich in alten Bouillonculturen die weniger widerstandsfähigen Individuen $\mathrm{zu}$ Grunde gehen, und dass nur die kräftigsten Exemplare vermehrungsfähig bleiben.

Wie dem aber auch sei, wenn wir einigermassen den Wirkungswerth unserer frisch abgeimpften Culturen rorauswissen wollen, so impfen wir jetzt nicht mehr von Bouillonculturen, namentlich nicht von älteren, sondern von Agarculturen ab.

Dass wir gerade zwei Tage lang im Brütschrank gewachsene Culturen nehmen, hat auch seine besonderen Gründe. Es ist leicht verständlich, 
dass mit der Zahl der lebensfähigen Diphtheriebacillen, welche in einer flüssigen Cultur vorhanden sind, auch die Infectionskraft gleicher Mengen derselben sich ändern wird.

Nun sieht man häufig, dass am ersten Tage nach der Impfung: scheinbar in ganz gleicher Weise geimpfte Bouillonröhrchen ein sehr differentes Wachsthum zeigen; wir glauben, dass dies darin seine Ursache hat, dass bei Ueberimpfungen mit einer Platinnadel, oder mit einer Oese nie gleich viel Bacillen in die frischen Culturen hinüberkommen, ja, dass die Differenzen in dieser Beziehung recht grosse sein können; von der Zahl der übergeimpften Bacillen ist aber zweifelsohne die Reichlichkeit des Wachsthums in der ersten Zeit in hohem Grade abhängig. Wartet man dann jedoch noch länger, bis zum Endé des zweiten Tages, so gleichen sich die groben Differenzen wieder aus.

Die Ursache dafür, dass wir nicht ältere Bouillonculturen wählen, ist darin begründet, dass wir die Ansammlung von Diphtheriegift und damit die Complication der Infection mit der Intoxication vermeiden wollen.

Um endlich eine recht genaue Dosirung der zur Infection verwendeten Flüssigkeit zu ermöglichen, injiciren wir nicht kleinere Mengen als $0.25^{\mathrm{ccm}}$; dazu bedarf es selbstrerständlich einer Verdünnung der Cultur; wollen wir beispielsweise ein Meerschweinchen mit $0.0125^{\mathrm{cm}}$ inficiren, so bedarf es einer 20fachen Verdünnung, damit diese Quantität in $0 \cdot 25^{\mathrm{cm}}$ enthalten ist.

Was nun den Virulenzgrad unserer Agarcultur betrifft, ron welcher wir gegenwärtig abimpfen, so ist derselbe wieder um mehr als das Doppelte grösser, als der an denjenigen Agarculturen beobachtete, die wir zur Zeit des internationalen Congresses in London (August cr.) benutzten. Damals theilten wir mit, dass $0.025 \mathrm{~cm}$ einer 2tägigen Cultur genügten. um ein Meerschweinchen in 4 bis 5 Tagen zu tödten; gegenwärtig reicht dazu schon 0.01 bis $0.0125^{\mathrm{cm}}$ aus. Die Meerschweinchen Nr. 1 bis 50 sind demnach mit dem 3 bis 4 fachen der tödtlichen Minimaldosis inficirt worden.

Wir fügen noch hinzu, dass entsprechend der Vermehrung der Virulenz der zur Impfung verwendeten Stammcultur die Production des specifischen Diphtheriegiftes immer mehr gesteigert worden ist.

Vor 11/4. Jahr mussten wir, um mit dem Filtrat einer drei Monate alten Diphtheriebouilloncultur ein Meerschweinchen in 3 bis 4 Tagen an Diphtherievergiftung sterben zu lassen, ca. $4^{\mathrm{cm}}$ subcutan injiciren; gegenwärtig genügt. 0.1 cem dazu, also der 40. Theil jener Menge.

Um in unseren Protokollen die langathmigen Bezeichnungen bei der Behandlung der Thiere mit Diphtherie-Bouilloncultur und mit Diphtheriegift zu vermeiden, haben wir von Abkürzungen Gebrauch gemacht. 
D.B.C. bedeutet darnach - wenn nichts anderes hinzugefügt ist - in der Zeit vom April bis October 1891 - eine zwei Tage lang im Brütschrank gewachsene Diphtherie-Bouilloncultur mit solchem Wirkungswerth, dass $0.025^{\mathrm{cm}}$ genügen, um ein Meerschweinchen in ca. vier Tagen zu tödten; in der Zeit vom October bis zum Abschluss dieser Arbeit eine ebensolche Cultur, aber mit einem derartigen Werth, dass die einfache sicher tödtliche Minimaldosis $0.0125^{\mathrm{cm}}$ beträgt. - D.G. bedeutet Diphtheriegift.

Weiterhin kommen noch folgende Abkürzungen in den Tabellen vor:

M. = Meerschweinchen; K. = Kaninchen; H. = Hammel; M.S. = Meerschweinchenserum; K.S. = Kaninchenserum; H.S. = Hammelserum.

Die nähere Bezeichnung der Serumarten durch die Hinzufügung der Nummer desjenigen Thieres, von dem sie herstammen und des Datums, an welchem die Blutabnahme zum Zweek der Serumgewinnung stattgefunden hat, wird ohne Weiteres verständlich sein.

Für die Leistungsfähigkeit des Serums wird stets diejenige Verhältnisszahl angewendet werden, welche ausdrückt, für wieviel lebend Körpergewicht Meerschweinchen $1 \mathrm{~cm}$ Serum subcutan injicirt genügt, um zu verhindern, dass das Thier bei 24 Stunden später erfolgter Infection mit der tödtlichen Minimaldosis einer zweitägigen DiphtherieBouilloncultur irgend welche Krankheitserscheinungen bekommt. Es liegt in der Natur der Sache, dass diese Zahl nie eine genaue sein kann; wir heben das ausdrücklich hervor, um solchen Vorwürfen zu entgehen, wie sie dem einen von uns gemacht wurden bei seiner Art der zahlenmässigen Bestimmung der relativen Giftigkeit von chemischen Präparaten; wir hoffen aber, genügend detaillirte Angaben gemacht zu haben, um demjenigen, der in experimenteller Arbeit geübt ist, die Beurtheilung der Fehlergrenzen dieser Berechnung in genügender Weise zu ermöglichen.

Soweit bis jetzt unsere Erfahrungen reichen, lassen sich eine Reihe von Schlüssen daraufhin ziehen, wie der therapeutische Effect eines Serums sein wird, dessen immunisirenden Werth wir kennen. Die Ergebnisse, zu denen wir nach dieser Richtung gekommen sind, haben wir schon oben resumirt, und wir finden dieselbe in unseren neuen Versuchsreihen bestätigt. Wir verweisen zum Beweise hierfür insbesondere auf das gleichmässige Resultat der therapeutischen Versuche bei den Thieren Nr. 38 bis 45 , bei welchen diejenige Serummenge $(1: 100)$, welche zur Immunisirung ausreichte ( $\mathrm{Nr} .36 \mathrm{u}$. 37) zur definitiven bezw. glatten Heilung bei gleich nach der Infection erfolgter Einspritzung nicht ausgereicht hat; wir verweisen andererseits aber auf die Meerschweinchen Nr. 58 und 59 in der zweiten Versuchsreihe, die entsprechend unserer Vorausberechnung keinerlei Reactionserscheinungen zeigten, als sie bei 
gleicher Serumbehandlung nicht mit $0.04^{\mathrm{cem}}$ sondern mit $0.02 \mathrm{cem}$ D.B.C. inficirt wurden.

Einige andere Schlussfolgerungen aus unseren Versuchen werden wir noch am Schluss der Arbeit zu besprechen haben.

\section{Versuchsreihe.}

M. Nr.1. Gew. 7./IX. $1891725^{\mathrm{grm}} ; 17 . /$ X. $570^{\mathrm{grm}} ; 19 . /$ XII. $525^{\mathrm{grm}}$.

Datam

1890. Sept. inficirt mit 0.2 D.B.C. und geheilt mit AuNaCl.

11./XII. Blutentnahme von $8^{\mathrm{cm}}$ aus Carotis sin.; vergl. Vortrag von Behring: "Ueber Desinfection am lebenden Organismus.“ Internationaler Congress in London.

1891. 30./ $/$. Blutentziehung aus Carotis dextr.

2./VI. $0.4 \mathrm{~cm}$ D. G.; nur Oedem (4 gleichbehandelte andere M. starben nach 2 bis $4 \mathrm{Tg}$.)

10./VII. $3^{\mathrm{ecm}} 1$ Stunde auf $65^{\circ}$ erhitzte D.B.C. (krank; Controlund 14 andere $\mathrm{M}$. sterben an gleicher Dosis.)

25./VII. resultatlose Unterbindung der Aa. femorales behufs Blutentnahme.

9./VIII. 0.025 D.B.C.; keine Reaction; Control-M. todt nach $3 \mathrm{Tg}$.

10./X. 0.025 D.B.C.

29./X. 0.05 D.B.C. (Control-M. todt nach $2 \mathrm{Tg}$ )

20./XII. abgemagert, scheinbar gesund.

21./XII. 0.04 D.B.C.

24:/XII. keine Reaction.

27./XII. kurzathmig.

29./XII. Blutentziehung ca. $8^{\mathrm{ccm}}$.

Sectionsbefund: Tod durch Verbluten. - Inhalations-Tuberculose. Tuberculöse Pneumonie der Lungen; sehr starke Schwellung der Bronchialdrüsen; sehr grosse Milz mit tuberculösẹn Herden. Am wenigsten weit ist der tuberculöse Process in der Leber fortgeschritten.

Immunisirende Wirkung des Serums $=1: 400$. Diphtheriebacillen in das Serum verimpft wachsen darin sehr üppig und sind sehr virulent.

\section{Epikrise zu Nr. 1.}

Dieses Thier ist dasselbe, über welches auf dem diesjährigen internationalen Congress in London berichtet wurde.

Es war bis zum September d.J. trotz der mehrfachen Blutentziehungen aus den Carotiden und trotz der Oblitteration der Aa. femorales ganz gesund.

Dann aber magerte es $a b$ und zeigte auch sonst mancherlei Symptome des Krankseins, namentlich zeitweilige Kurzathmigkeit. 
Gleichwohl hatte es noch 3 malige starke Diphtherieinfectionen überstanden, als wir es am 21./XII. 1891 von Neuem mit soviel Diphtheriecultur inficirten, dass sie etwa das 3 fache der tödtlichen Mlinimaldosis repräsentirte. Auch diese Infection wurde reactionslos vertragen. Indessen die $\dot{A} b-$ magerung nahm stetig zu und von 725 grm im September fiel das Körpergewicht auf $525 \mathrm{grm}$ am 19./XII., am 28./XII. 1891 betrug es $527 \mathrm{grm}$. An diesem Tage fiel es Herrn Geh. Rath Koch auf, dass das Thier abgesehen ron der Kurzathmigkeit auch sonst nicht gesund aussah, und trotz des Fehlens aller localen Reactionserscheinungen seitens der Diphtherieinfection musste der Vermuthung Raum gegeben werden, dass uns das Thier bald eingehen würde.

In Folge dessen entschlossen wir uns, dasselbe durch reichliche Blutentziehung zu tödten, einmal um noch das vermuthlich sehr wirksame Blut zu gewinnen, dann aber auch um die Ursache der Abmagerung und Allgemeinerkrankung festzustellen.

Da wir nun die Carotiden, aus denen wir sonst bei Meerschweinchen das Blut zu entnehmen pflegen, gänzlich oblitterirt fanden, so fingen wir das Blut aus dem Herzen auf, gewannen dabei leider aber nur $8^{\mathrm{cm}}$.

Es genügte diese Menge jedoch, eine Reihe von Versuchen anzustellen, deren Resultat oben kurz mitgetheilt ist.

Die an sich schon recht erhebliche immunisirende Leistungsfähigkeit von 1:400 hat unseren Erwartungen doch nicht ganz entsprochen. Bei richtiger Würdigung der Vorgeschichte des Thieres musste das Serum desselben mehr leisten, als das des Meerschweinchens Nr. 3 (s. d.); und wir sind darnach der Meinung, dass zwar der Tuberculoseprocess die Diphtherieimmunität nicht aufhebt, aber doch eimen vermindernden Einfluss auf dieselbe ausüben kann, sei es direct, sei es durch die mit demselben verbundenen allgemeinen Ernährungsstörungen.

Die Inhalationstuberculose war mit ihren eigenartigen Befunden nach dem Urtheil von Geheimrath R. Koch sehr markant ausgesprochen; die Infection ist mehrere Monate zurück zu datiren.

Von den bei diphtherieverendeten Thieren zu findenden Erscheinungen war bei der Section keine Spur vorhanden.

M. Nr. 2. Gew. 9./X. $1891910^{\mathrm{grm}} ; 21 . / \mathrm{XII} .705^{\mathrm{grm}}$.

Datum

Im Herbst 1890 durch $\mathrm{AuNaCl}$ von einer Diphtherieinfection geheilt.

1891. 20./VII. $0.05^{\mathrm{ccm}}$ D.B.C. (Control-M. todt nach $3 \mathrm{Tg}$.); darnach Infiltration, Abscessbildung und lange Krankheit mit nachfolgender allmählicher Genesung.

10./X. 0.025 $\mathrm{cm}$ D.B.C. (Control-M. todt nach 2 Tg.). 
21./XII. $0 \cdot 04^{\mathrm{cem}}$ D.B.C.

24./XII. keine Reaction.

1892.

4./I. gesund; Gew. $715 \mathrm{grm}$.

M. Nr. 3. Gew. 7./XI. $1891625 \mathrm{grm} ; 4 . / \mathrm{I} .1892530^{\mathrm{grm}}$.

1891. 9./VI. $0.005^{\mathrm{grm}}$ festes D.G. (Kalkpulver).

5./VII. $2 \cdot 5^{\mathrm{cem}}$ D.B.C. 1 Std. auf $75^{\circ}$ erhitzt intraabdominell.

8./VII. 5 cem D.B.C. 1 Stunde auf $65^{\circ}$ erhitzt subcutan.

10./X. $0.025^{\mathrm{com}}$ D.B.C. (Control-M. todt nach $2 \mathrm{Tg}$.).

21./XII. $0 \cdot 04^{\mathrm{em}}$ D.B.C.

24./XII. keine Reaction.

28./XII. eiteriger Nasenfluss.

29./XII. Blutentnahme von 15 cem aus Carot. sin.; darnach scheintodt.

30./XII. hat sich wieder erholt; frisst gut, nimmt an Gewicht ab.

\section{Epikrise.}

Dieses Meerschweinchen fürchteten wir zu verlieren, weil es eitrigen Ausfluss aus der Nase bekam. Es ist uns das ein Symptom für eine Erkrankung der. Brustorgane, an welcher sehr viele Thiere im hiesigen Institut verloren gehen. Sie sterben unter den Erscheinungen der Dyspnoe nach voraufgegangener starker Abmagerung. Bei der Section findet man in der Regel eitrige Pleuritis und Pericarditis; im Eiter lassen sich dann massenhaft Stäbchen nachweisen. Diese Krankheit decimirt uns auch solche Meerschweinchen, welche ohne jede Behandlung längere Zeit in unseren Ställen gehalten werden.

Es sollte nun von diesem Thiere aus der linken Carotis eine Blutentziehung bis zur Verblutung vorgenommen werden. Als jedoch ca. $15 \mathrm{ccm}$ ausgeflossen waren, stand die Blutung; das Thier athmete nicht mehr und wir glaubten, dass es sterben würde. Gleichwohl wurde noch die Carotis legal unterbunden und die Wunde zugenäht.

Nach einigen Minuten traten wieder Athembewegungen ein, und am folgenden Tage zeigte das Meerschweinchen ganz unverminderte Fresslust.

Bis auf nicht unbeträchtliche Abmagerung und ein trockenes Ekzem, das über die ganze Nase bis fast zu den Augen verbreitet ist, scheint es jetzt gesund $\mathrm{zu}$ sein.

Das aus dem Blute gewonnene Serum ist in hohem Grade wirksam. Bei $1: 500$ ist die Heilwirkung noch nicht erschöpft (s. Nr. 56).

Auch in dem Serum dieses Thieres wachsen Diphtheriebacillen sehr üppig.

M. Nr. 4. Gew. 4./IX. 1891530 grm.

4./IX. $0.5^{\mathrm{cem}}$ Lösung von D.G. 0.4 Proc. $\mathrm{JCl}_{3} 75$ Minuten Einwirkung.

5./IX. $1 \cdot 0^{\mathrm{cem}}$

14./IX. $1 \cdot 0^{\mathrm{cm}}$

,

$"$

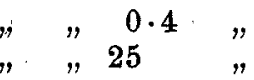

$" 20$ Stunden

" 10 Tage

"


IMMUNISIRUNG vON VERSUCHSTHIEREN BEI DIPHTHERIE.

Datum

18. IX. 1.0 $0^{\mathrm{em}}$ Lösung von D.G. 0.4 Proc. JCl. 24 Stunden Einwirkung.

4. X. $1 \cdot 0^{\mathrm{cm}}$

14. X. $1 \cdot 0 \mathrm{cem}$

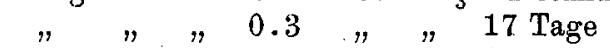

0.25

26./X. $0.04 \mathrm{~cm}$ D.B.C. (Control-M. todt nach" 66 Stunden).

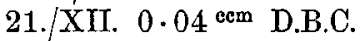

24.jXII. keine Reaction.

M. Nr. 5. Gew. 4./IX. $1891355^{\mathrm{grm}}$.

4. IX. $0 \cdot 5^{\mathrm{ccm}}$ Lösung von D.G. 0.25 Proc. $\mathrm{JCl}_{3} 100$ Minuten Einwirkung.

14. IX. $0 \cdot 7^{\mathrm{ccm}}$

18./IX. $1 \cdot 0^{\mathrm{cm}}$

1./X. $1 \cdot 0^{\mathrm{cm}}$

14. X. $0 \cdot 5^{\mathrm{com}}$

19./X. 0.05 em D.B.C. (Control-M. todt "nach" 60 Stunden).

21. XII. $0.04^{\mathrm{ecm}}$ D.B.C.

22./XII. kein Oedem.

24. XII. gesund.

M. Nr. 6, Gew. 4./IX. $1891455^{\mathrm{grm}}$; 26./XII. $540 \mathrm{grm}$.

4. IX. $1.0 \mathrm{~cm}$ Lösung von D.G. 1/50 0.05 Proc. $\mathrm{JCl}_{3} 2$ Minuten Einwirkg.

6./IX. $1 \cdot 0 \mathrm{~cm}$

14. IX. $0.5^{\mathrm{cm}}$

18./IX. $1 \cdot 0^{\mathrm{cm}}$

4. X. $1 \cdot 0^{\mathrm{ccm}}$

14./X. $1 \cdot 0 \mathrm{ccm}$

26. X. $0.04^{\mathrm{eem}}$

21. XII. $0 \cdot 04^{\mathrm{cm}}$ D.B.C.

24./XII. gesund.

M. Nr. 7. Gew. 4./IX. $1891230^{\mathrm{grm}}$.

5./IX. $0.5^{\mathrm{cm}}$ Lösung von D.G. $1 / 100.05 \mathrm{Proc}^{\mathrm{JCl}} \mathrm{JCl}_{3} 5$ Minuten Einwirkg.

14./IX. $0 \cdot 2 \mathrm{cem}$

18./IX. $1 \cdot 0^{\mathrm{ccm}}$

11. $/$ X. $0 \cdot 5^{\mathrm{ccm}}$

19. X. $0.05^{\mathrm{cem}}$ D. $\ddot{B} . \mathrm{C}$

21./XII. $0 \cdot 04^{\mathrm{cem}}$ D.B.C.

24./XII. gesund.

M. Nr. 8. Gew. 8./IX. $1891270 \mathrm{grm}$.

8. IX. $1^{\mathrm{cm}}$ Lösung von D.G. 0.4 Proc. $\mathrm{JCl}_{3} 44$ Std. Einwirkg. intraabdom.

14. IX. $0.2^{\mathrm{eem}}, \quad, \quad, 0 \cdot 15, \quad, 10 \mathrm{Tg} . \quad, \quad$ subcutan.

18./IX. $1.0^{\mathrm{ccm}}, \quad ", \quad 0.4 \quad, \quad " 24$ Std. " "

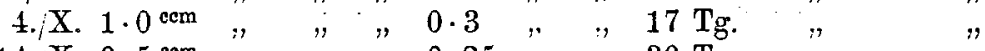

14. X. $0.5^{\mathrm{cm}} ", \quad, \quad 0.25, \quad, \quad 30 \mathrm{Tg} . \quad, \quad$, "

26. X. $0 \cdot 04^{\mathrm{cm}}$ D.B.C.

21./XII. 0.04 cem D.B.C.

22./XII. Abends Respiration gestört; kait; krank. Todt nach 36 Stunden. 
M. Nr. 9. Gew. 6./IX. $1891260 \mathrm{grm}$.

8. IX. 1.0 cem Lösung von D.G. 0.4 Proc. $\mathrm{JCl}_{3} 44 \mathrm{Std}$. Einw. intraabdom.

\begin{tabular}{|c|c|c|c|c|c|c|c|c|c|}
\hline 14./IX. $0.2^{\mathrm{cen}}$ & & & & 0.15 & " & $"$ & $10 \mathrm{Tg}$. & $\eta$ & subcutan \\
\hline $18 . /$ IX. $1.0 \mathrm{~cm}$ & $"$ & $"$ & $"$ & 0.4 & $"$ & $"$ & 24 Std. & " & $"$ \\
\hline 4./X. $1.0^{\mathrm{cm}}$ & " & $"$ & $"$ & $0 \cdot 3$ & $"$ & $"$ & $17 \mathrm{Tg}$. & $"$ & $"$ \\
\hline $14 . /$ X. $0.5 \mathrm{ccm}$ & $\eta$ & $"$ & $"$ & $0 \cdot 25$ & $"$ & $"$ & $30 \mathrm{Tg}$. & $"$ & $"$ \\
\hline
\end{tabular}

21. XII. 0.04 D.B.C.

22./XII. Abends Respiration etwas gestört.

23./XII. schwerkrank.

24./XII. todt nach 3 Tagen.

M. Nr. 10. Gew. 6./IX. 1891255 grm.

8./IX. $1^{\text {can }}$ Lösung von D.G. 0.4 Procent $\mathrm{JCl}_{3} 44$ Std. Einwirkung.

14.IIX. $0.2^{\mathrm{cem}} ", \quad " \quad 0.15, \quad, 10 \mathrm{Tg}$.

18./IX. $1.0^{\mathrm{com}} "$ " $0.4 \quad " \quad$ " 24 Std. "

19./X. $0.05^{\mathrm{cem}}$ D.B.C.

21./XII. $0 \cdot 04 \mathrm{ccm}$ D.B.C.

23./XII. todt nach $36 \mathrm{Std}$.

M. Nr. 11. Gew. 14.jIX. $1891255^{\mathrm{grm}}$.

14./IX. $0 \cdot 2 \mathrm{~cm}$ Lösung von D.G. $0 \cdot 15$ Proeent $\mathrm{JCl}_{3} 10 \mathrm{Tg}$. Einwirkung.

18. IX. $1.0^{\mathrm{cem}} ", \quad " 0.4 \quad " 2 \pm$ Std. $"$

26.IX. 0.04 com D. B.C.

1./XII. 3 lebende Junge.

21./XII. $0.04 \mathrm{~cm}$ D.B.C.

22./XII. Abends kalt, krank, Respiration gestört; todt nach 25 Std. während der Injection von 5 ccm Serum in die Bauchhöhle.

Sectionsbefund: Pralle Ausdehnung des Herzbeutels durch wasserklare

Flüssigkeit; geringes Transsudat in der Brusthöhle; Verdichtung der oberen

Hälfte der linken Lunge und der Spitze der rechten. Nebennieren normal.

Leber blass. - An der Injectionsstelle leicht geröthete Infiltration.

M. Nr. 12. Gew. 18./IX. $1891430 \mathrm{grm} 25 . / \mathrm{XI} .395 \mathrm{grm}$.

18./IX. $1 \cdot 0^{\mathrm{cem}}$ Lösung von D.G. 0.4 Procent $\mathrm{JCl}_{3} 24$ Std. Einwirkung.

4./X. $1.0^{\mathrm{com}} \quad " \quad " 0.3 \quad, \quad " 17 \mathrm{Tg}$.

14./X. $5.0^{\mathrm{cem}} " \quad " \quad " \quad 0.3 \quad " \quad, \quad 30 \mathrm{Tg}$.

6./XI. $2.5 \mathrm{~cm}$ H.S." (II) $2 . / X I .0 .5$ Procent Carbol intraabdominell.

21./XII. $0.04 \mathrm{~cm} \mathrm{D.B.C.}$

24. XII. Infiltration, Bauchgeschwulst; schwerkrank.

26./XII. todt am 6. Tg.

I. Nr. 13. Gew. 18./IX. $1891230 \mathrm{grm}$.

18./1X. 1.4 em D.G.-Lösung 0.4 Procent $\mathrm{JCl}_{3} 24$ Std. Einwirkung; darnach sehr starkes Oedem mit uachfolgender Infiltration und Necrose an der Injectionsstelle; Panophthalmie rechts (3.; XI.). - Coordinationsstörungen. 
16./XI. scheinbar gesund.

21./XII. $0.04 \mathrm{cem}$ D.B.C.

$2 \% /$ XUI. starkes locales Oedem.

24. /XII. todt nach 3 Tagen.

M. Nr. 14. Gew. 1./X. 1891502 grm.

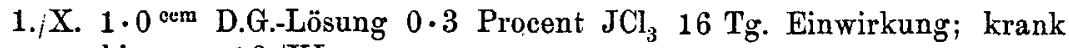
bis zum 16./XI.

21./XII. U.04 eem D.B.C.

22./XII. Abends Respiration gestört; krank.

23. IXII. todt nach 36 Std.

\section{Nr. 15 .}

24. X. $0 \cdot 35^{\mathrm{cm}}$ D.G.-Lösung $0 \cdot 1$ Procent $\mathrm{JCl}_{3} 50 \mathrm{Tg}$. Einwirkung; krank bis 25.: XI.

4./XI. $2 \cdot 5^{\mathrm{cm}}$ H.S. (II.) 2./XI. ohne Carbol intraabdominell.

21./XII. $0.04^{\mathrm{cem}}$ D.B.C.

22./XII. starkes locales Oedem.

24./XII. todt nach 3 Tagen.

M. Nr. 16 .

24./X. $0 \cdot 1^{\mathrm{ecm}}$ D.G.-Lösung $0 \cdot 1$ Procent $\mathrm{JCl}_{3} 50 \mathrm{Tg}$. Einwirkung; darnach sehr starke locale Infiltration; krank bis 16. $\mathrm{XI}$.

21./XII. $0.04^{\mathrm{ccm}}$ D.B.C.

22./XII. andeutungsweise Oedem.

24./XII. starke locale Reaction.

26./XII. todt am 6. Tage.

M. Nr. 17. Gew. 25./VII. $250^{\mathrm{grm}}$; 19./XII. $440^{\mathrm{grm}}$.

25./VII. $5^{\mathrm{cm}}$ Blut aus Carotis von K. Nr. XXXII intraabdominell.

30./VII. 0.05 cem D.B.C. (Control-M. todt nach 40. Std.). - Infiltration mit nachfolgender Schwarten- u. Necrosenbildung. - Krank bis 30./VU.

10./X. $0.025 \mathrm{em}$ D.B.C. (Control-M. todt nach 3 Tg.). - Keine Reaction. 21./XII. 0.04 esm D.B.C.

24./XII. gesund.

M. Nr. 18. Gew. 7.;X. $530^{\mathrm{grm}} ;$ 19./XII. $675^{\mathrm{grm}}$.

5./ VIII. $3^{\mathrm{com}}$ K.S. von K. XXXII intraabdominell.

9./VIII. $0.025^{\mathrm{cem}}$ D.B C. (Control-M. todt nach $4 \mathrm{Tg}$.); kleine Infiltration.

10. X. $0.025 \mathrm{cem}$ D.B.C. (Control-M. todt nach $3 \mathrm{Tg}$.); keine Reaction.

21./XII. $0.04 \mathrm{cem}$ D.B.C.

24./XII. gesund.

M. Nr. 19. Gew. 26./X. $250^{\mathrm{grm}}$; 19./XII. $440^{\mathrm{grm}}$.

25./X. $5 \mathrm{ccm}$ H.S. (I.) 23., X. intraabdominell.

26./X. $0.025 \mathrm{ccm}$ D.B.C. (Control-M. todt nach $10 \mathrm{Tg}$.); stets gesund.

21./XII. 0.04 cem D.B.C.

23./XII. todt nach 36 Stunden. 
M. Nr. 20. Gew. 28./X. $345^{\mathrm{grm}} ; 19 . / \mathrm{XII} .475 \mathrm{grm}$.

25./X. $5^{\mathrm{cem}}$ H.S. (I.) 23./X. intraabdominell.

26./X. $0.025 \mathrm{~cm}$ D.B.C. (Control-M. todt nach $10 \mathrm{Tg}$.); stets gesund.

21./XII. $0.04 \mathrm{cem}$ D.B.C.

24. XII. todt nach 36 Std.

M. Nr. 21. Gew. 4./XI. $175^{\mathrm{grm}}$.

4./XI. $3^{\mathrm{cm}}$ H.S. II (2./XI. 0.5 Proc. Carbol) intraabdominell; $0.03 \mathrm{ccm}$ D.B.C. (Control-M. todt nach $60 \mathrm{Std}$.)

21./XII. $0.04 \mathrm{cem}$ D.B.C.

22. XII. andeutungsweise Oedem; Abends Respiration gestört.

23./XII. todt nach $36 \mathrm{Std}$.

M. Nr. 22. Gew. 6/XI. $275^{\mathrm{grm}}$; 19./XП. $410^{\mathrm{grm}}$.

5./XI. 5 cem H.S. II (2./XI.) intraabdominell.

7./XI. 0.025 em D.B.C. (Control-M. todt nach $6 \mathrm{Tg}$.)

21./XП. $0.04 \mathrm{cem}$ D.B.C.

22./XII. Abends krank.

23./XII. todt nach 36 Std.

M. Nr. 23. Gew. 6./XI. $640^{\mathrm{grm}}$; 26 6 XII. $860^{\mathrm{grm}}$.

5./XI. $5^{\mathrm{cm}}$ H.S. II (2./XI.) intraabdominell.

7./XI. $0.05^{\mathrm{cm}}$ D.B.C. (Control-M. mit 0.025 D.B.C. todt nach $6 \mathrm{Tg}$.)

21./XII. $0.04 \mathrm{eem} \mathrm{D.B.C.}$

24./XII. gesund.

M. Nr. 24. Gew. 12./XI. $440^{\mathrm{grm}} ; 26 . / \mathrm{XII} .360^{\mathrm{grm}}$.

11./XI. $0.05^{\mathrm{cm}}$ (Control-M. todt nach $6 \mathrm{Tg}$.)

13./XI. krank; festes Oedem.

$5^{\mathrm{cem}}$ H.S. II (2./XI.) intraabdominell.

22./XI. Infiltration sehr stark; $3 \cdot 5^{\text {cen }}$ H.S. I (16./XI.) mit 0.5 Procent Carbol intraabdominell.

23. (XI. $3^{\mathrm{c}} \mathrm{cm}$ H.S. I (16. XI.) mit 0.5 Procent Carbol subcutan.

24. (XI. 3 ecm H.S. I (16./XI.) mit 0.5 Procent Carbol subcutan; an der Injectionsstelle der D.B.C. thalergrosse Necrose der Haut.

28./XI. $3^{\mathrm{cem}}$ H.S. I (16./XI.) mit 0.5 Procent Carbol subeutan.

20./XII. sehr abgemagert.

21. /XII. $3^{\mathrm{cm}}$ H.S. II (12./XII.) intraperitoneal.

30./XII. todt.

Sectionsbefund: Eitrige Pleuritis und Pericarditis, Pneumonie, weit vorgeschrittene fettige Degeneration der Leber. - Aeusserste Abmagerung. Weisse Nebennieren.

Todesursache: Stäbchenpneumonie, nicht Diphtherie; gegenüber ersterer Krankheit konnte selbstverständlich die Injection von H.S. nichts nützen. 
M. Nr. 25. Gew. 17./XI. $320 \mathrm{grm}$.

17./XI. $2.5 \mathrm{cem}$ H.S. I (16./XI.) mit 0.5 Procent Carbol intraabdominell. 0.04 em D.B.C. (Control-M. todt nach $60 \mathrm{Std}$.); 20./XI. starkes locales Oedem.

21. XII. $0.04^{\mathrm{eem}}$ D.B.C.

24./XII. todt nach 3 Tagen.

M. Nr. 26. Gew. 17./XI. $172^{\text {grm }}$.

17./XI. 2 cem H.S. I (16./XI.) 0.5 Procent Carbol intraabdominell.

$0.04{ }^{\mathrm{ecm}}$ D.B.C. (Control-M. todt nach $3 \mathrm{Tg}$.); 20./XII. starkes Oedem.

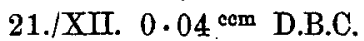

23./XII. todt nach $36 \mathrm{Std}$.

M. Nr. 27. Gew. 17./XI. $455^{\mathrm{grm}}$; 19./XII. $550^{\mathrm{grm}}$.

19./XI. $7 \cdot 5^{\mathrm{cm}}$ H.S. I (16./XI.) intraabdominell.

$0.025 \mathrm{~cm}$ D.B.C. (Control-M. todt am 21./XI.); 20./XI.geringes Oedem.

21./XII. 0.04 em D.B.C.

23./XII. todt nach 36 Std.

M. Nr. 28. Gew. 19./XI. $420^{\mathrm{grm}} ; 20 . / \mathrm{XII} .445^{\mathrm{grm}}$.

19./XI. $6.5 \mathrm{~cm}$ H.S. I (16./XI.) mit 0.5 Procent Carbol intraabdominell. $0.025^{\mathrm{cm}}$ D.B.C. (Control-M. todt am 21./XI.)

22./XI. geringes festes Oedem; $2 \cdot 2^{\text {em }}$ H.S. I (16./XI.) mit 0.5 Procent Carbol subcutan.

21./XII. $0 \cdot 04$ cem D.B.C.

23./XII. todt nach 36 Std.

M. Nr. 29. Gew. 19./XI. $425 \mathrm{grm} ; 20 . / \mathrm{XII} .525 \mathrm{grm}$.

19./XI. $10 \mathrm{~cm}$ H.S I (16./XI.) mit 0.5 Procent Carbol intraabdominell.

20./XI. $0.025^{\mathrm{ecm}}$ D.B.C. (Control-M. todt nach $48 \mathrm{Std}$.)

21. XII. $0.04 \mathrm{cem}$ D.B.C.

22. XII. todt nach 21 Std.

Sectionsbefund: Injectionsstelle blutig infiltrirt; Nebennieren nicht merklich verändert, Lungen marmorirt, im Gewebe rothe Stellen; gallertiges mässig reichliches Transsudat in den Pleurasäcken.

M. Nr. 30. Gew. 19./XI. $410^{\mathrm{grm}} ; 20 . /$ XII. $495^{\mathrm{grm}}$.

19./XI. $6^{\mathrm{ccm}}$ H.S. I (16./XI.) mit 0.5 Procent Carbol intraabdominell.

20./XI. $0.025 \mathrm{cem}$ D.B.C. (Control-M. todt nach $48 \mathrm{Std}$.)

22./XI. $2.5^{\mathrm{cein}}$ H.S. I (16./XI.) mit 0.5 Procent Carbol subcutan.

21. XII. $0.04 \mathrm{~cm}$ D.B.C.

23./XUI. todt nach 36 std.

Zeitschr. f. Hygiene. $\mathbf{x} I I$. 
M. Nr. 31. Gew. 3./XU. $215 \mathrm{grm}$.

3./XII. $2^{\mathrm{ccm}}$ H.S. II (2./XII.) intraabdominell. $0.05^{\mathrm{cm}}$ D.B.C. (Control-M. todt nach $40 \mathrm{Std}$.)

21. /XII. $0.04 \mathrm{~cm}$ D.B.C.

22./XII. kein Oedem.

24./XII. gesund.

M. Nr. 32. Gew. 3./XII. $260 \mathrm{grm}$.

3./XII. $2^{\mathrm{ecm}}$ H.S. II (2./XII.) subcutan. $0.05 \mathrm{~cm}$ D.B.C. (Control-M. todt nach $40 \mathrm{Std}$.)

5./XII. $1.5^{\mathrm{ccm}}$ H.S. II (2./XII.) subcutan.

6./XII. $3.0 \mathrm{~cm}$ H.S. II (2./XII.) intraabdominell; 6./XI. sehr krank.

21./XII. Bewegungen gestört, ziemlich grosse Schwäche; nekrotisches Hautstück noch nicht abgestossen. $0.04 \mathrm{cem}$ D.B.C.

22. (XII. starkes Oedem.

23./XII. todt nach $36 \mathrm{Std}$.

M. Nr. 33. Gew. 3./XI. $375^{\mathrm{grm}}$.

7./XUI. $2 \cdot 5^{\mathrm{cm}}$ H.S. II (2./XII.) intraabdominell. $0.03^{\mathrm{ecm}}$ D.B.C. (Control-M. todt nach $66 \mathrm{Std}$.)

21./XII. $0.04^{\mathrm{com}}$ D.B.C.

22./XII. andeutungsweise Oedem; Abends Respiration gestört.

23./XII. todt nach 36 Std.

M. Nr. 34. Gew. 17./XII. $300 \mathrm{grm}$.

17./XII. $3 \mathrm{ccm}$ H.S. II. (12./XII.) 0.4 Procent Carbol intraabdominell.

21./XII. $0.04 \mathrm{cem}$ D.B.C.

24./XII. gesund.

M. Nr. 35. Gew. 17./XII. $315^{\mathrm{grm}}$.

17./XII. $3^{\text {com }}$ H.S. II (12./XII.) mit 0.4 Procent Carbol intraabdominell.

21./XII. $0.04 \mathrm{cem}$ D.B.C.

28./XII. bis auf ganz geringe Infiltration gesund.

29./XII. im Kaninchenstall todtgedrückt?

Sectionsbefund: Geringes Transsudat in der Brusthöhle; Nebennieren weiss; linke Lungenspitze geröthet; im Uebrigen normale Lungen.

Nicht an Diphtherie gestorben!

M. Nr. 36. Gew. 17./XII. $300 \mathrm{grm}$.

17./XII. $4.5^{\mathrm{ccm}}$ H.S. II (12./XII.) mit 0.4 Procent Carbol intraabdominell. 21./XII. $0.04 \mathrm{cem}$ D.B.C.

24./XII. gesund.

M. Nr. 37. Gew. 17./XUI. $205^{\mathrm{grm}}$.

18./XII. $2^{\mathrm{cm}}$ H.S. II (12./XII.) mit 0.4 Procent Carbol intraabdominell.

21./XII. $0.04^{\mathrm{ccm}}$ D.B.C.

23. XII. todt nach 36 Std. 
Bei diesem Thiere müssen wir annehmen, dass das Blutserum nicht in die Peritonealhöhle, sondern in den Darm bei der Injection gelangt ist. Dass ein solches Ereigniss vorkommen kann, ist, wenn man sich die Verhältnisse vergegenwärtigt, leicht zu verstehen. Indessen ist es uns doch ausserordentlich selten passirt und bei genügender Vorsicht lässt es sich auch wohl ziemlich sicher vermeiden.

M. Nr. 38 . Gew. 21./XII. $340 \mathrm{grm}$.

21./XII. $3^{\mathrm{ccm}}$ H.S. II (12./XII.) intraabdominell. $0.04 \mathrm{~cm}$ D.B.C.

24./XII. starkes Oedem, krank.

26./XII. diffuse Infiltration.

31./XII. todt. 4 cem H.S. II (12./XII.) subeutan.

Sectionsbefund: Sehr ausgebreitete feste Infiltration; reichliches Transsudat in den Pleurasäcken; rothe Nebennieren.

M. Nr. 39. Gew. 21./XII. $330 \mathrm{grm}$.

21./XII. $3^{\mathrm{cem}}$ H.S. II (12./XI.) intraabdominell. $0.04 \mathrm{~cm}$ D.B.C.

24./XII. gesund bis auf mässige Infiltration.

26./XII. umschriebenes kleines Infiltrat; gesund.

29./XI. starke Infiltration; krank.

31./XI. todt. - Typischer Diphtheriebefund.

M. Nr. 40. Gew. 21./XU. $605 \mathrm{grm}$.

21./XII. $3^{\mathrm{cm}}$ H.S. II (12./XII) intraabdominell. $0.04^{\mathrm{cem}}$ D.B.C.

24. XII. starke locale Infiltration; munter.

26./XII. starke Bauchgeschwulst; sehr krank.

2./I. 92. todt. - Typischer Diphtheriebefund.

M. Nr. 41. Gew. 21./XII. $310^{\mathrm{grm}}$.

21./XII. $3^{\mathrm{ccm}}$ H.S. II (12./XII.) subcutan. 0.04 ecm D.B.C.

22./XII. kein Oedem.

24./XII. mässige Infiltration; munter.

26./XII. diffuses Infiltrat.

3./I. 92. todt.

M. Nr. 42. Gew. 21./XII. $210 \mathrm{grm}$.

21./XII. $3^{\mathrm{cm}}$ H.S. II (12./XU.) intraabdominell. $0.04 \mathrm{cem}$ D.B.C.

22./XII. kein Oedem.

24./XII. umschriebene mässige Infiltration; munter.

26./XII.

15./I. 92. gesund.

,

; sonst scheinbar gesund. 
M. Nr. 43. Gew. 21./XII. $390^{\mathrm{grm}}$.

21./XII. $5^{\mathrm{cem}}$ H.S. I (16./XII.) intraabdominell. $0 \cdot 04^{\mathrm{cem}}$ D.B.C.

22./XII. leichtes Oedem; Abends Respiration gestört.

23./XII. todt nach 36 Std.

M. Nr. 44 (mager und schwach). Gew. 21./XII. $495 \mathrm{grm}$.

21./XII. $3^{\mathrm{com}}$ H.S. II (12./XII.) intraabdominell. $0.04^{\mathrm{cem}}$ D.B.C.

22./XII. leichtes Oedem.

23./XII. todt nach 36 Std.

Sectionsbefund: Sehr weit vorgeschrittene fettige Degeneration der Leber; fibrinös-eitriges Exsudat auf den Lungen und dem Pericardium, daneben etwas flüssiges Transsudat in den Pleurasäcken. - Nebennieren weiss. An der Infectionsstelle geringes Oedem.

M. Nr. 45. Gew. 21./XII. $235^{\mathrm{grm}}$.

21./XII. $3^{\mathrm{ccm}}$ H.S. II (12./XII.) intraabdominell. $0.04^{\mathrm{cem}}$ D.B.C.

24./XII. mässige locale Infiltration; munter.

26./XII. gesund.

15./I. 92. gesund.

M. Nr. 46. Gew. 21./XII. $260 \mathrm{grm}$.

21./XII. $0.04^{\mathrm{cem}}$ D.B.C. (Abends $5 \mathrm{Uhr}$.)

22./XII. $5 \mathrm{ccm}$ H.S. II (12./XUI.) 0.4 Procent Carbol V.-M. $10 \mathrm{Uhr}$. Abends krank; Respiration gestört; schlaff, kalt.

23./XII. todt nach 36 Std.

M. Nr. 47. Gew. 21./XII. $355^{\mathrm{grm}}$.

21./XI. $0.04^{\mathrm{eem}}$ D.B.C.

22./XU. $10 \mathrm{Uhr}$ Vm. starkes Oedem; $11 \mathrm{Uhr}$ Vm. $5^{\mathrm{cm}}$ H.S. II (12./XII.) 0.4 Proc. Carbol intraabdominell. - Abends Respiration gestört; schlaff, kalt, schwerkrank.

23./XII. todt nach ca. $30 \mathrm{Std}$.

II. Nr. 48. Gew. 21./XII. $680^{\mathrm{grm}}$.

21./XII. $0.04 \mathrm{cem}$ D.B.C. (Infection Abends $1 / 26 \mathrm{Uhr}$.)

22./XII. starkes Oedem.

todt nach ca. 29 Std.

M. Nr. 49. Gew. 21./XII. $390 \mathrm{grm}$.

21./XII. 0.04 cem D.B.C. (Infection Abends $1 / 26$ Uhr.)

22./XII. 10 Uhr Vm. starkes Oedem; $11 \mathrm{Uhr} \mathrm{Vm} .5^{\mathrm{cem}}$ H.S. II (12./XII.) mit 0.4 Proc. Carbol intraabdominell. - Abends Respiration gestört.

23./XII. todt nach $43 \mathrm{Std}$. 
M. Nr. 50.' Gew. 21./XII. $615 \mathrm{grm}$.

21./XII. $0.04 \mathrm{cem}$ D.B.C.

22./XII. starkes Oedem;

23. XII. todt nach ca. 30 Std.

M. Nr. 51 . Gew. 21./XI. $400 \mathrm{grm}$.

21. (XII. $0.04 \mathrm{~cm}$ D.B.C. (Abends $6 \mathrm{Chr}$.)

21. (XII. Morgens Oedem. - Todt $11 \mathrm{Uhr}$ Vm. (nach 19 Std.!)

Sectionsbefund: Locales Oedem; reichliches Transsudat in der Bauchhöhle, marmorirte, z. Th. atelectatische Lungen; Nebennieren geröthet.

Zur besseren Gesammtübersicht über dasjenige, was die eben mitgetheilten Versuchsprotokolle lehren können, geben wir nunmehr noch einige Erläuterungen.

Die Anordnung dieser grösseren Versuchsreihe I war bedingt durch unsere Absicht, Herrn Geheimrath Koch an bestimmten Beispielen zu demonstriren, wie weit wir jetzt mit unseren Experimenten in der Immunisirung und Heilung von Laboratoriumsthieren gekommen sind. Nun setat sich die wissenschaftliche Grundlage unserer Behandlungsmethode aus folgenden integrirenden Theilen zusammen.

Wir immunisiren zunächst diphtherieempfängliche Thiere.

Wir untersuchen dann von Zeit zu Zeit das Serum des Blutes der immunisirten Thiere auf seine immunisirende und heilende Leistungsfähigkeit.

Finden wir schliesslich dieselbe so gross, dass wir damit eklatante therapeutische Resultate bekommen können, dann suchen wir uns von den Eigenschaften und Fähigkeiten dieses Diphtheriemittels genauere Kenntniss zu verschaffen.

Der Endzweck unserer Versuche bleibt immer der, das Mittel in solcher Menge und Wirksamkeit zu gewinnen, dass damit auch beim Menschen die Diphtherie behandelt werden kann.

Man erkennt ohne Weiteres, dass für den einwandsfreien Beweis unserer Behauptung, ,jetzt soweit zu sein, dass an die Verwerthung unseres Diphtherieheilmittels auch beim Menschen gedacht werden könne," es genügt, wenn wir unser Mittel in applicabler Form fertig solchen Personen behufs eigener Prüfung in die Hand geben, die ein sachverständiges Urtheil über die hierhergehörigen Fragen haben.

Wenn dann zunächst bei Versuchsthieren bestätigt wird, dass dieses Mittel in der That ein specifisches Diphtherieheilmittel ist, welches von der Blutbahn aus überall im Körper die krankmachenden Wirkungen der Diphtheriebacillen aufhebt, wenn dann weiter bestätigt wird, dass dasselbe für das behandelte Individuum absolut unschädlich ist, dann haben wir zum Beweise jener Behauptung alles beigebracht, was billigerweise 
verlangt werden kann; und es ist sachlich. dabei ganz gleichgültig, wie wir zu unserem Heilmittel gekommen sind.

Man hört jetzt oft die Forderung erheben, dass bei Neueinführung eines Heilmittels dessen Zusammensetzung genau bekannt sein müsse, ja womöglich "dasselbe müsse rein dargestellt sein."

Nun, wir wissen selber noch gar nichts Genaues über die chemische Natur der im Blute wirksamen Heilkörper; und nur soweit sind wir darüber orientirt, dass wir selbst auf eine sogenannte „Reindarstellung" verzichten. ${ }^{1}$

Gleichwohl, wenn wir soweit gekommen sein werden, dass, auf das Körpergewicht eines Kindes berechnet, eine Einspritzung von wenigen Cubikcentimetern einer im Uebrigen indifferenten Flüssigkeit sichere Heilwirkung gegenüber einer sonst absolut tödtlichen Diphtherieinfection zu Stande bringt, - dann haben wir keine Sorge darum, dass das Mittel auch beim Menschen angewendet werden wird, auch wenn es nicht in seiner Zusammensetzung genau bekannt und nicht rein dargestellt ist, ja selbst wenn über seine Herkunft gar nichts bekannt wäre.

Soweit sind wir jetzt noch nicht; die grösste Wirkung, welche wir mit den bis jetzt untersuchten Serumsorten erzielt haben, ist die Heilwirkung des Serums von einigen Meerschweinchen mit $1: 1000$ bei sofort nach der Infection eintretender Behandlung und 1:400 nach dem Auftreten deutlicher und allgemeiner Erlirankung.

Wenn wir nun unter Berücksichtigung der Thatsache, dass der Mensch nicht in gleichem Grade wie die Meerschweinchen als diphtherieempfänglich angesehen werden kann, und dass die Infection in der Regel nicht so stark ist, wie wir sie künstlich machen, voraussetzen dürfen, dass die Heilung des Menschen leichter gelingen wird, als die der Versuchsthiere, so kommen wir doch noch zu recht erheblichen Zahlen für die Serummenge, die voraussichtlich zur Heilung eines schwer diphtheriekranken Kindes nothwendig ist.

Bei Zugrundelegung der Zahl 1:400 würden wir für ein Kind mit einem Körpergewicht von 20 Kilogr. noch 50 cm Heilserum gleich am Anfang verbrauchen mũssen und zur Weiterbehandlung dann wahrscheinlich noch ebensoviel.

Wir möchten noch besonders hervorheben, dass Niemand mit Sicherheit voraussagen kann, ob die Diphtherie des Menschen leichter oder schwerer durch unser Mittel zu heilen ist, als die der Versuchsthiere; wir

1 Deber die Ergebnisse unserer Versuche, wirksame Heilkörper aus dem Blute za isoliren, bezw. dieselben in concentrirtere Lösung zu bringen als diejenige, in welcher sie im Serum enthalten sind, werden wir in der demnächst erscheinenden Monographie über die Blatserumtherapie berichten. 
müssen aber mit der ungünstigeren Möglichleit rechnen und uns auch auf den Fail gefasst machen, dass nicht gleich die ersten Heilversuche unzweideutig positiv ausfallen.

Unter diesen Umständen und aus dem weiteren Grunde, weil wir selbst darauf verzichten, orientirende Vorversuche am Menschen zu machen, halten wir es für zweckmässig, demjenigen, der mit unserem Diphtherieheilmittel solche Versuche anstellen will, nicht bloss an Thieren die vollkommene Unschädlichkeit desselben zu demonstriren, sondern auch ihm ein selbstständiges Urtheil darüber zu verschaffen, dass die therapeutische Leistungsfähigkeit unseres Mittels einer noch nicht abzusehenden Steigerung fähig ist.

Für diesen Zweck aber ist es nothwendig, dass wir die Art der Gewinnung des Heilserums mittheilen.

Nach diesen Vorbemerkungen wird, wie wir hoffen, die mit der Anordnung der ersten Versuchsreihe verbundene Absicht verständlich sein.

Wir zeigen zunächst, dass durch eine besondere Art der Vorbehandlung Meerschweinchen dahin gebracht werden können, dass sie auf eine für Controlthiere (Nr. 46-51) schnell tödtlich wirkende Diphtherieinfection gar nicht reagiren $(\mathrm{Nr} .1-7)$. Wir entnehmen $z$ wei ron diesen immunen Thieren (Nr. 1 und Nr. 3) Blut und zeigen, dass man mit dem daraus gewonnen Serum andere Thiere (Versuchsreihe II, Nr. 54-57) sicher und glatt heilen kann.

Da wir ein einfaches und ganz sicheres Recept zur Erreichung der Immunität bei Meerschweinchen noch nicht geben können, so haben wir nicht bloss diejenigen vorbehandelten Thiere in die Versuchsreihe aufgenommen, welche nach unserer Ansicht schon einen hohen Grad von Immunität besitzen mussten, sondern auch solche, die verschiedene Uebergangsstufen repräsentiren, und wir haben bei allen die Art der Vorbehandlung genau angegeben.

Die Meerschweinchen Nr. 8 bis 11, welche wesentlich in der gleichen Weise vorbehandelt waren, wie die hochimmunen Thiere Nr. 4-7 unterscheiden sich dadurch von diesen, dass sie zwar die im October 1891 erfolgte Infection überstanden, jedoch lange Zeit darnach krank waren und dadurch documentirten, dass der Immunisirungsprocess bei ihnen noch nicht soweit vorgeschritten war, um einer starken Infection Widerstand zu leisten; es wird aber durch längeres Kranksein an Diphtherie erfahrungsgemäss die vorhandene Immunität nicht, bloss verringert, sondern sie kann ganz aufgehoben werden; während der Dauer der deutlichen Erkrankung sind diese Thiere sogar noch mehr diphtherieempfindlich als Controlthiere. Allmählich, mit der Wiederkehr der Gesundheit, wächst die Diphtheriewiderständigkeit und wird schliesslich sogar grösser als sie vorher gewesen 
ist. Das kann aber sehr lange dauern, lange noch über den Zeitpunkt hinaus, wo man ron Krankheitserscheinungen auch bei genauer Untersuchung nichts mehr wahrnehmen kann.

Es ist unter diesen Umständen begreiflich, dass, wenn man nicht sehr viel Geduld besitzt, es sehr leicht eintreten wird, dass man zu früh die Thiere auf Immunität prüft und dadurch verliert. In der That haben wir die ersten hochimmunen Thiere nur dem Zufall zu verdanken, dass durch vierteljährige Abwesenheit des einen von uns die Immunisirungsarbeit unterbrochen war, und dass wir darnach vorbehandelte und inficirte Thiere zur Untersuchung bekamen, die 4 bis 6 Monate sich selbst überlassen blieben. Wir hätten schwerlich bei ununterbrochener Thätigkeit der Versuchung widerstanden, schon früher und wahrscheinlich zu früh dieselben zu prüfen. Gegenwärtig, wo wir ohne Gefährdung des Lebens der im Immunisirungsprocess begriffenen Thiere ein sicheres Mittel besitzen, uns über den Grad ihrer Immunität Kenntniss zu verschaffen, indem wir nämlich die immunisirende Kraft ihres Blutes an anderen Thieren prüfen, durften wir uns schon den Luxus erlauben, einige Meerschweine zu opfern, um zu zeigen, wie viel Cautelen man anwenden muss, um positive Resultate zu bekommen.

Um unserem Zweifel an der genügenden Diphtheriewiderständigkeit vou Nr. 8 bis 11 Ausdruck zu geben, 'stellten wir dieselben hinter diejenigen Thiere, zu welchen wir ein grösseres Vertrauen hatten.

Es kommt dann (Nr. 12 bis 16) eine zweite Kategorie von Mreerschweinchen, die wie 4 bis 11 mit jodtrichloridbehandeltem Diphtheriegift jmmunisirt sind, und welche früher noch nicht eine für Controlthiere tödtliche Infection überstanden haben. Die detaillirte Besprechung dieser Meerschweine würde zu weit führen und ist wohl auch überflüssig, da Jedermann die sich ergebenden Schlussfolgerungen bei einem sorgfältigen Studium der Versuchsprotokolle selbst ableiten kann.

Eine dritte Kategorie umfasst solche Thiere, welche früher mit D.B.C. inficirt und durch Heilserum verschiedenen Ursprungs geheilt, oder die zuerst mit Serum immunisirt und später inficirt waren. Hier wussten wir selber nicht, wie die Ergebnisse sein würden. Es wird unsere Aufgabe sein, die jetzt gewonnenen Resultate für spätere Versuche nutzbar zu machen.

Eine vierte Kategorie (Nr. 34 bis 37) umfasst diejenigen Meerschweinchen, welche früher bloss Heilserum [von H. II, (12.;XII. 91)] bekommen hatten; wir schliessen aus dem Impferfolg dieser vier Thiere, dass, da zwei derselben sogar auf eine Infection mit mindestens dem dreifachen der tödtlichen Minimaldosis nicht reagirten, das Hammelserum sicher einen Immunisirungswerth von 1:100 besitzt. 
Aus den an den Meerschweinchen Nr. 38 bis 45 gemachten Beobachtungen haben wir entnommen, dass zur Heilung ron einer so starken Infection, wie sie hier stattfand, das Hammelserum II, (12./XII. 91) in der angewendeten Menge von nicht mehr als 1:100 nicht ausreiche, ${ }^{1}$ und noch weniger das zu früherer Zeit entnommene Hammelserum; indessen war auch bei den schliesslich verendeten Meerschweinchen der Verlauf ein solcher, dass wir danach erwarten durften glatte Heilung zu bekommen, wenn die Infection weniger stark gewählt wurde.

Mit dieser blossen Vermuthung haben wir uns aber nicht begnügt, sondern dieselbe an Nr. 58 und 59 in der folgenden Versuchsreihe auf ihre Richtigkeit geprüft. Daneben zeigen wir, dass bei Anwendung einer grösseren Serummenge $(1: 40)$ auch die Heilung bei vorgeschrittener Erkrankung an Diphtherie erreicht werden kann. (Nr. 60.)

Die Meerschweinchen Nr. 46 bis 51 sind sämmtlich wie Controlthiere zu betrachten, auch diejenigen, welche am folgenden Tage noch eine Seruminjection bekommen haben (Nr. 46, 47 und 49); sofort nachdem die Injectionen gemacht waren, starb ein Controlthier an typischer Diphtherie und die anderen wenige Stunden später. Der Krankheitsprocess war demnach bei allen am 21./XII. 91 nicht mit Serum behandelten Thieren - wider unser Erwarten - schon soweit vorgeschritten, dass mit so wenig Serum, wie wir bei der uns noch zur Verfügung stehenden beschränkten Menge in Anwendung bringen konnten, nicht eine Heilung zu ermöglichen war. $\mathrm{Ob}$ auch in diesem Stadium, wenn wir wirksameres Serum und dasselbe in grösserer Menge einspritzen, ein Heilerfolg noch möglich ist, darüber kann nur das Experiment Auskunft geben. Wir halten eine solche Möglichkeit noch njcht für ausgeschlossen.

\section{Versuchsreihe II.}

M. Nr. 52 (Controlthier). Gew. 31./XIr. $360^{8 \mathrm{rm}}$.

1891. 31./XII. $0.02 \mathrm{~cm}$ D.B.C.

$1892 . \quad 1 . /$ I. Oedem.

2./I. Sehr starkes Oedem, schlaff, kalt. Abends todt an Diphtherie.

M. Nr. 53 (Controlthier). Gew. 31./XII. $300^{\mathrm{grm}}$.

1891. 31./XII. $0.02 \mathrm{~cm}$ D.B.C.

$1892 . \quad 1 . /$ I. Oedem.

2./L. Morgens sehr starkes Oedem; schlaff; liegt auf dem Rücken. Mittags todt an Diphtherie.

${ }^{1}$ Anm. bei der Correctur. Die Meerschweine Nr. 42 und Nr. 45. welche das kleinste Körpergewicht besassen und dementsprechend verhältnissmässig die grösste Serummenge bekommen hattẹn, sind definitiv geheilt worden. 
M. Nr. 54. Gew. 31./XП. $230 \mathrm{grm}$.

1891. 31./XI. $0.02 \mathrm{~cm}$ D.B.C.

M.S. von Nr. $3(29 . / \mathrm{XII} .91) 1.5^{\mathrm{cm}}$ intraperitoneal.

1892. 2./I. keine Reaction.

6./1. gesund.

M. Nr. 55 . Gew. 31./XII. $275 \mathrm{grm}$.

1891. 31./XII. $0.02^{\mathrm{eem}}$ D.B.C.

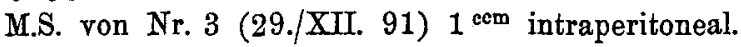

1892. 2./I. keine Reaction.

6./I. gesund.

M. Nr. 56. Gew. 31./XII. $250 \mathrm{grm}$.

1891. 31./XII. $0.02^{\mathrm{ccm}}$ D.B.C.

M.S. von Nr. 3 (29./XII. 91) $0.5^{\mathrm{cem}}$ intraperitoneal.

1892. 2./I. keine Reaction.

6./I. gesund.

M. Nr. 57. Gew. 31./XII. 440 grm.

1891. 31./XII. $0.02^{\mathrm{ccm}}$ D.B.C.

M.S. von Nr. 1 (29./XII. 91) $1.25 \mathrm{ccm}$ intraperitoneal.

1892. 2./I. leichte Infiltration an der Stelle der Infection.

6./I. kleine harte Inflitration; im Uebrigen gesund.

M. Nr. 58. Gew. 31./XIr. 300 grm.

1891. 31./XII. $0.02 \mathrm{~cm}$ D.B.C.

H.S. II (12./XII. 91) $3^{\mathrm{cem}}$ subcutan.

1892. 2./I. keine Reaction.

6./I. gesund.

M. Nr. 59. Gew. 31./XII. $265^{\mathrm{grm}}$.

1891. 31./XII. $0.02 \mathrm{~cm}$ D.B.C.

H.S. II (12./XII. 91) $2^{\mathrm{ccm}}$ intraperitoneal.

1892. 2./I. keine Reaction.

6./I. gesund.

M. Nr. 60 . Gew. 31./XIr. $200 \mathrm{grm}$.

1891. 31./XII. $0.02^{\mathrm{ecm}}$ D.B.C.

1892. 1./I. Abends $8 \mathrm{Uhr}$ Oedem an der Stelle der Infection mässig; das Thier fühlt sich schlaff an, aber noch warm; auf den Rücken gelegt bleibt es eine Weile liegen und zeigt gestörte Respiration; angestossen springt es wieder auf die Beine.

2./I. H.S. II (12./XII. 91) $5 \mathrm{com}$ intraperitoneal.

Infiltration an der Infectionsstelle stärker geworden. Das Thier ist noch krank.

3./I. kleine harte Infiltration; Respiration nicht merklich gestört; munter; bleibt nicht auf den Rücken liegen.

6./I. bis auf eine kleine harte Infiltration gesund. 
III. Immunisirungsversuche an Schafen.

H. Nr. 1. Gew. 14./IX. 30.2 Kilo; 4./I. 32.9 Kilo.

1891. 9./VIII. $15^{\mathrm{rem}}$ Blut von K. Nr. 9 intraabdominell.

21./VIII. $15^{\mathrm{ccm}}$ D.B.C. 13./VII. 1 Std. $90^{\circ}$ erhitzt subcutan.

24./VIII. $12^{\mathrm{ccm}}, \quad " 1,80^{\circ} ", \quad "$

27./VIII. $15^{\mathrm{com}} " \quad " \quad 1 \% 70^{\circ} ", \quad "$

15./IX. $13^{\mathrm{com}} " 11,65^{\circ} " 1$,

23./IX. 5 cem $" \quad \mathrm{JCl}_{3} 1: 25024$ std. Einwirkung.

8./X. 5 cem $" \mathrm{JCl}_{3} 1: 25024$,

23./X. Blutentnahme aus Ven. fac. dextr.; das Blutserum hat bei Meerschweinchen immunisirende Eigenschaften.

24./X. $\quad 8^{\mathrm{cm}}$ D.B.C. $\mathrm{JCl}_{3} 1: 25024$ std. Einwirkung.

7./XI. $8 \mathrm{cem}$ D.B.C. $\mathrm{JCl}_{3} 1: 25048$ "

19. $\mathrm{XI} \quad 5 \mathrm{~cm}$ D.B. JCl $1: 25048$

16./XI. Blutentnahme aus Ven. fac." sin.; das Serum heilt und immunisirt Meerschweinchen.

18./XI. 6 cem D.B.C. $\mathrm{JCl}_{3} 1: 30024$ std. Einwirkung.

29./XI. $7^{\mathrm{cem}}$ D.B.C. $\mathrm{JCl}_{3} 1: 30021 " \quad "$

3./XII. $10^{\mathrm{cm}}$ D.B.C. $\mathrm{JCl}_{3} 1: 30040, " \quad "$

8./XII. $6^{\mathrm{cm}}$ D.B.C. JCl. $1: 40096 ", \quad "$

18./XII. 5 $5^{\text {com }}$ D.B.C. JCl $1: 50024 ", "$

29. XII. 5 cem D.B.C. JCl $1: 60024$, ,

1892. 4./I. ganz gesund.

כ./I. Blutentnahme von $700^{\mathrm{cem}}$ aus der Ven. jug. dextr.

12./I. 5 cem D.B.C. $10 . / \mathrm{X}$. $+\mathrm{JCl}_{3} 1: 6008$ täg. Einwirkung.

14./I. $3 \cdot 5^{\mathrm{ccm}}$ D.G. $+\mathrm{JCl}_{3} 1: 50014$ täg. Einwirkung.

19./I. $5 \cdot 2^{\mathrm{cem}}$ D.G. $+\mathrm{JCl}_{3} 1: 50019 "$ "ganz gesund.

H. Nr. 2. Gew. 29./DX. 29.6 Kilo; 4./I. 92. 26.250 Kilo.

1891. 17./IX. 5 em D.B.C. $\mathrm{JCl}_{3} 1: 25024$ std. Einwirkung.

20./IX. $15^{\mathrm{cm}}$ D.B.C. $\mathrm{JCl}_{3} 1: 25024 "$,

23./IX. $1^{\mathrm{ccm}}$ D.B.C. $\mathrm{JCl}_{3} 1: 40024 ", "$

8./X. $5 \mathrm{~cm}$ D.B.C. $\mathrm{JCl}_{3} 1: 40026 "$,

24. X. 5 ecm D.B.C. $\mathrm{JCl}_{3} 1: 40024 "$,

2./XI. Blutentnahme aus Ven. fac. dextr.

7./XI. $7 \mathrm{~cm}$ D.B.C. $\mathrm{JCl}_{3} 1: 25024$ std. Einwirkung.

12./XI. 5 cem D.B.C. $\mathrm{JCl}_{3} 1: 30040 "$,

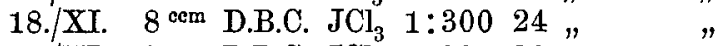

29./XI. 9 cem D.B.C. $\mathrm{JCl}_{3} 1: 30020 "$,

2. XII. Blutentnahme aus Ven. fac. sin.

3./XII. $10^{\mathrm{cm}}$ D.B.C. $\mathrm{JCl}_{3} 1: 30048$ std. Einwirkung.

8./XII. $2^{\mathrm{ecm}}$ D.B.C. $\mathrm{JCl}_{3} 1: 40024 "$ "

$8 \mathrm{cem}$.D.B.C. $\mathrm{JCl}_{3} 1: 30024$,

12./XI. Blutentnahme aus Ven. jugul. ext. dextr.

19./XII. Gewichtsabnahme auf 24.85 Kilo.

1892. 4./I. ganz gesund; Gewicht $26 \cdot 25$ Kilo.

5./I, $5 \mathrm{~cm}$ D.B.C. $10 . / \mathrm{X} .+\mathrm{JCl}_{3} 1: 400$. 
1892. 12./I. 5 cem D.B.C. 10./X. $+\mathrm{JCl}_{3} 1: 5008$ täg. Einwirkung.

14./I. $2 \cdot 5^{\mathrm{cm}}$ D.G. $+\mathrm{JCl}_{3} 1: 50015$ täg. Einwirkung.

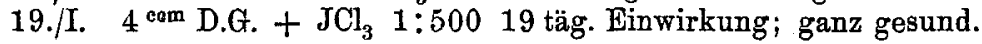

H. Nr. 3. Gew. 30./XI. 22.65 Kilo; 4./I. 23.04 Kilo.

1891. 20./XI. 1 com D.G. $+\mathrm{JCl}_{3} 1: 30024$ std. Einwirkung.

29./XI. 3 ccm D.B.C. $+\mathrm{JCl}_{3} 1: 30020 "$ "

3./XII. 5 $5^{\mathrm{cm}}$ D.B.C. + $\mathrm{JCl}_{3} 1: 30040 ", "$

8./XII. 5 com D.B.C. $+\mathrm{JCl}_{3} 1: 3004$ täg. "

18. XII. $99^{\mathrm{em}}$ D.B.C. $+\mathrm{JCl}_{3} 1: 30024$ std. "

29./XII. 5 cem D.B.C. $+\mathrm{JCl}_{3} 1: 40024, "$,

1892. 5./I. 5 cem D.B.C. $+\mathrm{JCl}_{3} 1: 40024 " "$ "

12./I. $5 \mathrm{~cm}$ D.B.C. $+\mathrm{JCl}_{3} 1: 4008$ täg. "

14./I. $1.5^{\mathrm{ccm}}$ D.G. $+\mathrm{JCl}_{3} 1: 50014 ", "$

19./I. $3 \mathrm{ccm}$ D.G. $+\mathrm{JCl}_{3} 1: 50019 "$,

Ausser der II. Versuchsreihe (an Meerschweinchen), welche als Ergänzung der I. Versuchsreihe anzusehen ist, haben wir noch (III) die Immunisirung von denjenigen drei Hammeln mitgetheilt, die wir mit gütiger Erlaubniss des Hrn. Prof. Rubner im hiesigen hygienischen Institut unterbringen durften, wo dieselben auf unsere eigenen Kosten gehalten werden.

Die Demonstration der in der vorliegenden Arbeit mitgetheilten Versuchsreihen (I und II) an Meerschweinchen erfolgte im Institut für Infectionskrankheiten mit den Mitteln desselben. 